\title{
Simultaneous inhibition of JAK and SYK kinases ameliorates chronic and destructive arthritis in mice
}

Alba Llop-Guevara 1* Mónica Porras', Carla Cendón ${ }^{1,2}$, Irene Di Ceglie” ${ }^{3}$ Francesco Siracusa ${ }^{2}$, Federica Madarena ${ }^{4}$, Vagelis Rinotas ${ }^{5}$, Lluís Gómez ${ }^{1}$, Peter L. van Lent ${ }^{3}$, Eleni Douni ${ }^{5,6}$, Hyun Dong Chang ${ }^{2}$, Thomas Kamradt ${ }^{4}$ and Juan Román ${ }^{1}$

\begin{abstract}
Introduction: Despite the broad spectrum of antirheumatic drugs, RA is still not well controlled in up to $30-50 \%$ of patients. Inhibition of JAK kinases by means of the pan-JAK inhibitor tofacitinib has demonstrated to be effective even in difficult-to-treat patients. Here, we discuss whether the efficacy of JAK inhibition can be improved by simultaneously inhibiting SYK kinase, since both kinases mediate complementary and non-redundant pathways in RA.

Methods: Efficacy of dual JAK + SYK inhibition with selective small molecule inhibitors was evaluated in chronic G6Pl-induced arthritis, a non-self-remitting and destructive arthritis model in mice. Clinical and histopathological scores, as well as cytokine and anti-G6PI antibody production were assessed in both preventive and curative protocols. Potential immunotoxicity was also evaluated in G6PI-induced arthritis and in a 28-day TDAR model, by analysing the effects of JAK + SYK inhibition on hematological parameters, lymphoid organs, leukocyte subsets and cell function.

Results: Simultaneous JAK + SYK inhibition completely prevented mice from developing arthritis. This therapeutic strategy was also very effective in ameliorating already established arthritis. Dual kinase inhibition immediately resulted in greatly decreased clinical and histopathological scores and led to disease remission in over $70 \%$ of the animals. In contrast, single JAK inhibition and anti-TNF therapy (etanercept) were able to stop disease progression but not to revert it. Dual kinase inhibition decreased Treg and NK cell counts to the same extent as single JAK inhibition but overall cytotoxicity remained intact. Interestingly, treatment discontinuation rapidly reversed such immune cell reduction without compromising clinical efficacy, suggesting long-lasting curative effects. Dual kinase inhibition reduced the Th1/Th17 cytokine cascade and the differentiation and function of joint cells, in particular osteoclasts and fibroblast-like synoviocytes.

Conclusions: Concurrent JAK + SYK inhibition resulted in higher efficacy than single kinase inhibition and TNF blockade in a chronic and severe arthritis model. Thus, blockade of multiple immune signals with dual JAK + SYK inhibition represents a reasonable therapeutic strategy for RA, in particular in patients with inadequate responses to current treatments. Our data supports the multiplicity of events underlying this heterogeneous and complex disease.
\end{abstract}

Keywords: Arthritis, JAK, SYK, Small molecule inhibitors, Anti-TNF therapy, Fibroblast-like synoviocytes, Osteoclasts, Memory cells

\footnotetext{
* Correspondence: alballop@gmail.com

'Draconis Pharma S.L., Calle Pallars 179, Barcelona, Spain

Full list of author information is available at the end of the article
} 


\section{Introduction}

Many patients with rheumatoid arthritis (RA) continue with persistently active disease. The conventional disease-modifying anti-rheumatic drugs (DMARDs), most commonly methotrexate (MTX), non-steroidal anti-inflammatory drugs (NSAIDs) and steroids, can inhibit local inflammatory symptoms but have little or insufficient long-lasting systemic effects. This prompted the emergence of biologic agents targeting specific intercellular signals, such as antagonists of TNF, IL-6 and IL-1 $\beta$, which apart from their anti-inflammatory effects directly reduce the pathogenic activity of synovial cells. Biologic agents targeting specific immune cells, such as modulators of B cell and T cell activity, were approved for RA patients not responding adequately to oral DMARDs or other biologic agents. While biologic agents have greatly improved the effectiveness of RA treatment, $30-40 \%$ of patients still do not have an appropriate response and, therefore, have interruptions in treatment [1]. Indeed, their required chronic use increases the risk of developing cancer and infection, and can cause drug resistance. In addition, biologic agents are expensive, have long half-lives and must be injected or infused, which highlights the need for better therapies.

Small molecule drugs, such as inhibitors of protein kinases, appear to be a good alternative due to their ability to immunomodulate multiple key intracellular signals. Furthermore, these chemical compounds $(<1 \mathrm{kDa})$ are orally available and have a short half-life, which facilitates treatment modulation. Persuasive preclinical data support the targeting of specific members of the mitogenactivated protein kinase (MAPK) (e.g., p38- $\alpha$ ) and PI3K/ Akt/mTOR (p1108) pathways but none of the inhibitors have progressed to phase III clinical studies due to lack of efficacy in RA patients and concerns about toxicity (reviewed in [2, 3]). The focus is now placed on kinases higher in the signaling cascade, such as the non-receptor cytoplasmic tyrosine kinases Janus kinase (JAK) and the spleen tyrosine kinase (SYK).

The JAK family in mammals includes the closely related isoforms JAK1, JAK2, JAK3 and TYK2 (tyrosine kinase 2), which homo/heterodimerize and bind to cytokine receptors. The JAK/STAT signaling pathways mediate the effects of many cytokines/interferons and growth factors important in RA (e.g., IL-2, IL-6, IL-7, IL10, IL-12, IL-15, IL-21, IL-23, interferons (IFNs), granulocyte macrophage colony-stimulating factor (GM-CSF)) and regulate the activity of hemopoietic and joint resident cells. In fact, the relevance of some of these signals has been validated in the clinics through their blockade using specific biologic drugs $[4,5]$. It is, thus, not surprising that JAK inhibitors have proved efficacious in animal models of arthritis [6,7], and in clinics [8,9]. Indeed, the small pan-JAK inhibitor tofacitinib (CP-690,550) was approved for the treatment of moderate to severe RA in patients who do not respond to MTX or conventional synthetic and biological DMARDs [10, 11]. JAK inhibition has demonstrated high efficacy, as approximately $60-70 \%$ RA patients experience clinical improvement with at least $20 \%$ response according to American College of Rheumatology criteria (ACR20 response) [12], even in non-responders to anti-TNF treatment (ACR20 of $48 \%$ ) [13]. As such, Lee et al. recently suggested that tofacitinib could be used as firstline monotherapy for RA [14].

SYK kinase is required for the signal transduction of receptors that associate with transmembrane proteins containing immunoreceptor tyrosine activation motifs (ITAM), i.e., the $\mathrm{B}$ cell receptor, $\mathrm{T}$ cell receptor and certain Fc receptors primarily present in granulocytes, dendritic cells (DCs) and macrophages. SYK additionally mediates signaling by integrins and members of the lectin/selectin families [15] and is involved in the activity of non-immune cells, such as fibroblast-like synoviocytes (FLS) and vascular endothelial cells [16-18]. As SYK is implicated in several pathways linked to RA pathogenesis, SYK inhibition is viewed as a plausible therapeutic strategy. To our knowledge, selective SYK inhibitors, such as PRT062607 (Portola/Biogen Idec), have shown encouraging preclinical data [19] but their potential efficacy in RA patients has not been evaluated. Here, we investigated whether the high efficacy of JAK inhibition could be improved by concurrently inhibiting SYK. To this end, we used potent and selective small molecule inhibitors of pan-JAKs (tofacitinib) and SYK (PRT062607) either in combination or alone, which were tested, for the first time, in a destructive and non-remitting arthritis murine model $[20,21]$.

\section{Methods}

\section{Induction and scoring of arthritis}

DBA/1 mice (six w.o. males from Janvier, France) were immunized subcutaneously (s.c.) $(100 \mu \mathrm{l}$ at each side of the base of the tail) with $400 \mu \mathrm{g}$ recombinant human (rhu) glucose-6-phosphate isomerase (G6PI) emulsified in complete Freund's adjuvant (CFA, Sigma-Aldrich, St. Louis, MO, USA) on day 0 , as previously described [20]. The indicated amount of antigen was mixed with CFA in a 1:1 ratio (v/v) and emulsified with a Polytron. When specified, regulatory $\mathrm{T}$ cells (Tregs) were depleted injecting intraperitoneally (i.p.) $400 \mu \mathrm{g}$ anti-CD25 Ab (PC61.5, BioXcell, West Lebanon, NH, USA) 11 and 8 days before immunization [21].

The mouse weight was recorded and the clinical score was evaluated over time. Each paw section was scored separately, and these scores were all added together as follows:

Total score per mouse $=($ Sum of scores of 2 wrists +2 ankles (i.e., $\max 12))+($ Sum of scores of 2 metacarpals 
+2 feet (i.e., $\max 12))+($ Number of inflamed fingers $(\max 8)+$ toes $(\max 10) / 2$ (i.e., $\max$ score of 9$))$.

For each paw section, a score of 0 to 3 was assigned, where 0 indicates no clinical signs of arthritis (healthy state), 1 and 2 indicate mild/intermediate swelling and redness of the paw, and 3 indicates massive swelling, redness and burst skin.

All experiments with mice were approved by the Animal Experimentation Ethical Committee of Draconis Pharma, the Animal Experimentation Commission of the Generalitat de Catalunya (Catalonian Government) or the German federal state institution Landesamt für Gesundheit und Soziales.

\section{T cell-dependent antibody response (TDAR) model}

CD-1 mice (six to eight w.o. females from Janvier, France) were immunized on day 0 with $300 \mu \mathrm{g}$ of keyhole limpet hemocyanin (KLH, Sigma-Aldrich, subplan$\operatorname{tar}$ injection of $30 \mu \mathrm{l})$. On day 14, mice were sacrificed and blood, plasma and spleens were obtained.

\section{Treatments}

The kinase inhibitors Tofacitinib (JAKi) and PRT-062607 (SYKi) were synthesized by Aptonchem Co. Ltd. (Hangzhou, China) or in house (Draconis Pharma), respectively. These compounds were diluted in water, sonicated for 5 minutes and given orally (p.o.) $(20 \mathrm{mg} / \mathrm{kg} \mathrm{JAKi}$ and $30 \mathrm{mg} / \mathrm{kg}$ SYKi) once daily (QD) starting on day 0 or 12 , unless otherwise specified. We corrected the amount of each compound used by the molecular weight (MW) of the free amine: $\mathrm{MW}$ of JAKi $=504.49 \mathrm{~g} / \mathrm{mol}$ (free amine $312.37 \mathrm{~g} / \mathrm{mol}$ ) and MW of SYKi $=453.50 \mathrm{~g} / \mathrm{mol}$ (free amine $393.45 \mathrm{~g} / \mathrm{mol}$ ). Prednisolone (Sigma-Aldrich, $3 \mathrm{mg} / \mathrm{kg}$ ) was also diluted in water and given p.o. QD. The soluble dimeric human TNFR p75-IgG-Fc fusion protein (etanercept, Enbrel ${ }^{\circ}$, Pfizer, Thousand Oaks, CA, USA) was diluted in PBS and given s.c. $(10 \mathrm{mg} / \mathrm{kg})$ every third day.

\section{Sample collection}

Samples were obtained at the indicated time points. Inguinal lymph nodes and spleens were weighted and single cell suspensions were made in Roswell Park Memorial Institute (RPMI)1640 medium (Life technologies, ThermoFisher Scientific, Eugene, OR, USA, supplemented with $10 \%$ FBS, glutamine, $100 \mathrm{U} / \mathrm{ml}$ penicillin, $100 \mathrm{mg} / \mathrm{ml}$ streptomycin) by mechanical disruption of the tissue with a syringe plunger on a $40-\mu \mathrm{m}$ cell strainer. Peripheral blood was collected in tubes with $0.5 \% \mathrm{~K}_{2}$-EDTA, hematological parameters analyzed by Celltac E analyzer (Nihon Khoden, Tokyo, Japan) and plasma stored at $-80{ }^{\circ} \mathrm{C}$ for cytokine and Ig quantification. Ankle swelling was measured using a dial-gauge caliper (Peacok, Ozaki MFG Co. Ltd., Tokyo, Japan); the average thickness of both hind legs was used. The right hind limb of each mouse was fixed in $10 \%$ formalin and then decalcified with Osteomoll (Merck Millipore) for histopathological assessment.

\section{Cytokine production by splenocytes}

Splenocytes were plated in triplicates $\left(8 \times 10^{5}\right.$ cells/well in 96-well flat-bottom plates) and re-stimulated with either $20 \mu \mathrm{g} / \mathrm{ml} \mathrm{rhu}$ G6PI or PBS in RPMI medium supplemented with $10 \% \mathrm{FBS}, 100 \mathrm{U} / \mathrm{ml}$ penicillin and $100 \mu \mathrm{g} /$ $\mathrm{ml}$ streptomycin at $37^{\circ} \mathrm{C}$ in $5 \% \mathrm{CO}_{2}$ for $72 \mathrm{~h}$. When indicated, splenocytes from non-treated arthritic mice were also exposed to $0.5 \mu \mathrm{M}$ of JAKi and $0.5 \mu \mathrm{M}$ of SYKi for $72 \mathrm{~h}$. Supernatants were collected and murine IFN $\gamma$, IL$17 \mathrm{~A}$ and IL-6 were measured by ELISA (BD, Franklin Lakes, NJ, USA, and Affymetrix, Santa Clara, CA, USA and eBioscience, San Diego, CA, USA), according to manufacturer's protocols.

\section{G6PI- and KLH-specific Ig ELISA}

Plasma levels of G6PI- and KLH-specific antibodies were measured by ELISA. Briefly, 96-well flat-bottom plates were coated with $5 \mu \mathrm{g} / \mathrm{ml}$ of G6PI or $10 \mu \mathrm{g} / \mathrm{ml}$ of $\mathrm{KLH}$ in carbonate buffer $\left(0.1 \mathrm{M} \mathrm{Na}_{2} \mathrm{CO}_{3}\right.$ and $\mathrm{NaHCO}_{3}$, $\mathrm{pH}$ 9.5) overnight at $4{ }^{\circ} \mathrm{C}$, washed with $\mathrm{PBS}$ containing $0.05 \%$ Tween-20 (Sigma-Aldrich) and incubated with a blocking buffer (2 \% BSA (Sigma-Aldrich) in PBS) for $1 \mathrm{~h}$ to saturate non-specific binding sites. Serial 5-fold or 10 -fold dilutions of the plasma in PBS $+0.05 \%$ Tween + $2 \%$ BSA were added for $2 \mathrm{~h}$ followed by $1 \mathrm{~h}$ incubation with isotype-specific $\mathrm{Ab}$ with peroxidase (goat antimouse Fcy-or Fc $\mu$-specific Ab-HRP, Jackson ImmunoResearch, Suffolk, UK). After washing, the substrate 3,3'$5,5^{\prime}$ tetramethylbenzidin (TMB) (BD) was added, the reaction was stopped with $1 \mathrm{M} \mathrm{H}_{2} \mathrm{SO}_{4}$ and the absorbance was determined at $450 \mathrm{~nm}$ with a reference wavelength of $570 \mathrm{~nm}$.

\section{Immunophenotyping by flow cytometry}

Cell surface phenotyping was performed by using antimouse antibodies to CD3, CD4, CD8, CD19, CD11c, CD11b, MHCII, CD86, CD49b, CD25, CD44, CD138 and/ or fixable live/dead. For intracellular markers, cells were fixed, permeabilized and stained with anti-Foxp3, CD40L, IFN $\gamma$, IL-2, TNF $\alpha$, 5-Bromo-2'-deoxyuridine (BrdU), ovalbumin (OVA), $\mathrm{k}$ and/or $\lambda$. Cells were analyzed with a FACS Calibur or a LSR Fortessa flow cytometer (BD Biosciences) and data were analyzed using FlowJo software.

\section{Cell-mediated cytotoxicity (CDC) assay}

Murine splenocytes (effector cells, EC) were isolated from treated and untreated mice. Target cells (TC, YAC-1 cell line) were labeled with $2.5 \mu \mathrm{M}$ CFSE fluorescent dye (Life technologies) to separate them 
from the EC population. Untreated splenocytes were treated in vitro for $1 \mathrm{~h}$ at $37{ }^{\circ} \mathrm{C}$ with JAKi + SYKi or anti-TNF, as indicated. Then, labeled TC were coincubated with EC (ratio of 1 TC:10 EC) for $4 \mathrm{~h}$ and the dye PI (Life technologies) was added to discriminate live and dead cells.

\section{Phagocytosis assay}

Peripheral blood mononuclear cells (PBMCs) were isolated from human buffy coats by Ficoll density gradient. Cells $\left(2 \times 10^{6}\right.$ cells/tube $)$ were pre-treated with JAKi and/or SYKi for $1 \mathrm{~h}$. Media were removed and replaced with $1 \mathrm{mg} / \mathrm{ml}$ Red pHrodo $^{\mathrm{TM}}$ BioParticles ${ }^{\circ}$ suspension (Life Technologies) and incubated for $1.5 \mathrm{~h}$ at $37^{\circ} \mathrm{C}$. Phagocytosis of particles was quantified by flow cytometry.

\section{Gene expression}

Total RNA was purified from splenocytes using the PureLink RNA Mini kit (Ambion, ThermoFisher Scientific, Carlsbad, CA, USA) and the concentration and purity were assessed using a Safire spectrophotometer (Tecan, Männedorf, Switzerland). RNA $(1 \mu \mathrm{g})$ was retro-transcribed to cDNA using High-Capacity cDNA Reverse Transcription kit (Life technologies) following manufacturer's instructions. RANKL, IFN $\gamma$ and IL-6 expression were evaluated by quantitative real-time PCR using TaqMan Universal Master Mix and a 7500 Real Time PCR System (Applied Biosystems, ThermoFisher Scientific). Relative quantification was determined using the comparative method: $18 \mathrm{~S}$ ribosomal RNA was used as the housekeeping gene (Mm04277571_s1). Taqman probes for RANKL, IFNY and IL6 were Mm00441906_m1, Mm00801778_m1 and Mm00446190_m1, respectively (Applied Biosystems).

\section{Histopathological assessment}

Tissue samples were paraffin-embedded and longitudinal microsections were stained with H\&E (Merck Millipore), according to standard procedures. A score of 0 (normal) to 5 (strongly affected) was given based on the degree of inflammation, bone erosion, cartilage damage and pannus formation in tarsus and phalanges, as previously described [22, 23]. Experienced pathologists at AnaPath (Spain) processed the tissues and performed the blinded histopathological assessment.

\section{Fibroblast-like synoviocyte (FLS) isolation, stimulation and invasion assay}

Small joints from Treg-depleted mice at day 56 postimmunization were dissected and digested in $1 \mathrm{mg} / \mathrm{ml}$ collagenase type IV solution for $2 \mathrm{~h}$ (Worthington Biochemical Corp., Lakewood, NJ, USA 250 U/mg). FLS were cultured in DMEM (Sigma-Aldrich) supplemented with $10 \%$ FBS, $100 \mathrm{U} / \mathrm{ml}$ Penicillin/Streptomycin (Jena Bioscience, Jena, Germany) and $10 \mathrm{mM}$ Hepes (Serva,
Heidelberg, Germany). All the FLS used were between passages 4 and 5 . FLS were plated $\left(5 \times 10^{4}\right.$ cells/well in 24-well plates) and stimulated with $10 \mathrm{ng} / \mathrm{ml} \mathrm{rmTNF- \alpha}$ and $50 \mathrm{ng} / \mathrm{ml}$ of rmIL-17A (both Peprotech, London, UK) or left unstimulated. All cells were also treated with $0.5 \mu \mathrm{M}$ JAKi and/or SYKi; dimethyl sulfoxide (DMSO) only was used as a control. After $24 \mathrm{~h}$ of incubation, the supernatants were harvested and IL-6, matrix metalloproteinase-3 (MMP-3) and MMP-9 were quantified by ELISA (reagents from eBioscience, San Diego, CA, USA and Peprotech for IL-6; commercial DuoSet kits from R\&D Systems, Minneapolis, MN, USA for MMPs).

To test FLS invasiveness, a transwell system was used. ThinCerts $^{\mathrm{Tm}}$ inserts with $8-\mu \mathrm{m}$ pores (Greiner bio-one, Frickenhausen, Germany) were coated with a bovine collagen solution (PureCol ', Advanced BioMatrix, Carlsbad, CA, USA; $10 \times$ MEM, Gibco, ThermoFisher Scientific, Waltham, MA, USA; sodium bicarbonate $7.5 \%$, Gibco) and put in 24-well plates. FLS $\left(2 \times 10^{4}\right.$ cells/well) resuspended in culture medium without FBS in the presence of $0.5 \mu \mathrm{M}$ of JAKi and/or SYKi or DMSO only, were seeded on top of the collagen matrix. Culture medium with $10 \%$ FBS was used as chemoattractant. After $48 \mathrm{~h}$ of incubation, the cells that did not migrate were removed from the upper part of the insert with a cotton swab and the lower part of the insert was stained with crystal violet. The percentage of invaded area was calculated using the program Fiji, as described [24].

\section{Osteoclast differentiation and bone resorption assay}

Bone marrow cells were collected after flushing out of femurs and tibiae, subjected to gradient purification using ficoll-paque (GE Healthcare, Little Chalfont, Buckinghamshire, UK), plated in 96-well plates at a density of $6 \times 10^{4}$ cells/well and cultured in $\alpha \mathrm{MEM}$ medium (Gibco) containing $10 \%$ FBS supplemented with $40 \mathrm{ng} /$ $\mathrm{ml}$ rank ligand (RANKL) (R\&D Systems) and $25 \mathrm{ng} /$ $\mathrm{ml} \mathrm{M-CSF}$ (R\&D Systems) [25] in the presence or absence of CP and PRT compounds for 5 days. To visualize osteoclasts, cell cultures were stained with tartrateresistant acid phosphatase (TRAP), using an acid phosphatase leukocyte (TRAP) kit (Sigma-Aldrich).

To assess osteoclast activity, bone marrow cells were seeded on $650-\mu \mathrm{m}$-thick bovine cortical bone slices $\left(10^{5}\right.$ cells/slice $)$ in $\alpha$ MEM supplemented with $5 \%$ FBS, $20 \mathrm{ng} / \mathrm{ml}$ RANK-L and M-CSF (30 ng/ml). Medium was refreshed after 3 days. Differentiated osteoclasts were treated with DMSO or $0.5 \mu \mathrm{M}$ of JAKi and/or SYKi on day 5 and bone resorption was assessed $48 \mathrm{~h}$ later. Osteoclasts were lysed with water and mechanically removed by sonicating the bone slices in $10 \% \mathrm{NH}_{3}$ for 20 minutes. Finally, bone slices were washed, incubated for 10 minutes with $10 \%$ hydrated 
potassium aluminium sulfate, washed again and stained with Coomassie blue (PhastGel Blue R-350; GE Healthcare Bioscience, Uppsale, Sweden) in order to visualize the pits of resorption. Five micrographs per slice were acquired with a digital camera mounted on an inverted light microscope and the percentage of eroded area was quantified using the program Leica Application Suite (version 4.3.0).

\section{Memory cell}

BALB/c mice (Charles River, Germany) were immunized i.p. with $100 \mu \mathrm{g}$ OVA (Sigma-Aldrich) in $100 \mu \mathrm{l}$ alum (ThermoFisher Scientific) at day 0. On day 21, mice were boosted with $100 \mu \mathrm{g}$ OVA in $100 \mu \mathrm{l}$ alum. From day 20 to 35, mice received $1 \mathrm{mg} / \mathrm{ml}$ BrdU (Sigma-Aldrich) dissolved in drinking water to label newly generated plasma cells (i.e., plasma cells generated after boost). From day 35 to 46, mice were treated with $20 \mathrm{mg} / \mathrm{kg} \mathrm{CP}$ and/or $30 \mathrm{mg} / \mathrm{kg}$ PRT (p.o. QD). On day 46 , single cell suspensions were generated from spleen and bone marrow and stained for flow cytometry. For the ex vivo re-stimulation assay, cells were plated in complete RPMI medium in 12 -well plates $\left(10^{7}\right.$ cells/well) and restimulated for $6 \mathrm{~h}$ with $100 \mu \mathrm{g}$ OVA. Brefeldin A (BioLegend, London, UK) was added after the first $4 \mathrm{~h}$ and finally stained for flow cytometry.

\section{Statistical analysis}

Data are expressed as mean \pm standard error of the mean and were analyzed and graphed with Prism software version 5 (GraphPad, La Jolla, CA, USA). Statistical analysis was calculated using Student's $t$ test (unpaired, twotailed) and one-way or two-way analysis of variance (with the Dunnett or Bonferroni post hoc test). Differences were considered statistically significant when the $p$ value was $<0.05$.

\section{Results}

Dose selection of potent and selective small JAK and SYK inhibitors

We used tofacitinib (CP-690,550, designed by Pfizer) as a selective pan-JAK inhibitor (JAKi) and PRT062607 (Portola Pharmaceuticals Inc. and Biogen Idec Inc.) to specifically inhibit SYK (SYKi), or their combination (JAKi + SYKi). In Additional file 1, we show data obtained to determine the doses of inhibitors to be further used for in vivo studies. Briefly, we first confirmed the potency and selectivity of these inhibitors in biochemical and cellular assays (half maximal inhibitory concentration $\left(\mathrm{IC}_{50}\right)(\mathrm{JAK})$ approximately $0.02 \mu \mathrm{M}$ and $\mathrm{IC}_{50}(\mathrm{SYK})$ approximately $0.5 \mu \mathrm{M}$ ). We also determined their efficacy in standard acute arthritis models in mice; namely the collagen-induced arthritis (CIA) model, which strongly relies on $\mathrm{T}$ cell function and therefore eases the study of JAK inhibition $\left(\mathrm{ED}_{50}\right.$ (JAK) approximately $11 \mathrm{mg} / \mathrm{kg}$ QD), and the collagen antibody-induced arthritis (CAIA) model for SYK inhibition, as it requires processing of anti-type II collagen antibodies and immune complexes via FcR. Based on these results, we decided to use a dosage of $20 \mathrm{mg} / \mathrm{kg}$ of tofacitinib (JAKi) and $30 \mathrm{mg} / \mathrm{kg}$ of PRT062607 (SYKi) QD. A single oral dose of tofacitinib or PRT062607 in naive mice resulted in a rapid increase of plasma levels $\left(t_{\max }=1-3 \mathrm{~h}\right)$, reaching maximal concentrations that did not compromise kinase selectivity, and were completely cleared daily. Therefore, the selected doses guaranteed high efficacy while maintaining selectivity.

\section{Dual JAK + SYK inhibition prevents G6PI-induced arthritis}

To test the efficacy of dual JAK + SYK inhibition, we chose a novel and well-accepted murine model of arthritis induced by the systemic antigen G6PI. Immunization is achieved by administering G6PI along with CFA subcutaneously. The resulting acute, self-limited type of arthritis [20] can be switched deliberately to a non-self-remitting and destructive type by transiently depleting Treg cells prior to disease induction [21]. This chronic model is characterized by exacerbated clinical signs of inflammation (redness and paw swelling), joint deformations and higher levels of T helper (Th1) and Th17 cytokines compared to the acute type (see [21] and Additional file 2). Here, we were interested in mimicking severe and nonself-remitting disease, as it better represents human disease; therefore, we used the chronic G6PI model.

In order to study the impact of kinase inhibition on arthritis development, daily oral treatment with JAKi and/or SYKi was started upon immunization (see a diagram of this experimental protocol in Additional file 2). Figure 1a shows that mice receiving SYKi developed moderate and persistent arthritis compared to vehicle controls and ended with $40 \%$ lower clinical scores. Mice treated with JAKi had mild inflammation of the paws, except for the toes and fingers, for a week only, as clinical signs were resolved in all mice after 17 days of treatment. As a measure for the aggregate effect of these treatments over time, the average area under the clinical score curve decreased by $94 \%$ with JAKi, but by only $33 \%$ with SYKi. The greatest effects were observed with the dual inhibition of JAK + SYK, which prevented all mice from developing arthritis. None of the mice had inflammation of the toes/fingers and only $30 \%$ were scored with incipient swelling of the wrists/ankles for at most 4 days. Accordingly, lymph node weights were significantly decreased compared to the progressively bigger ones in arthritic controls over time (Fig. 1b). In the spleen, the $\mathrm{CD} 11 \mathrm{c}^{\mathrm{hi}} \mathrm{MHCII}^{+}$dendritic cell pool (not shown), and consequently the number of activated $\left(\mathrm{CD}^{+} 6^{+}\right)$DCs (Fig. 1c), were reduced in mice treated 


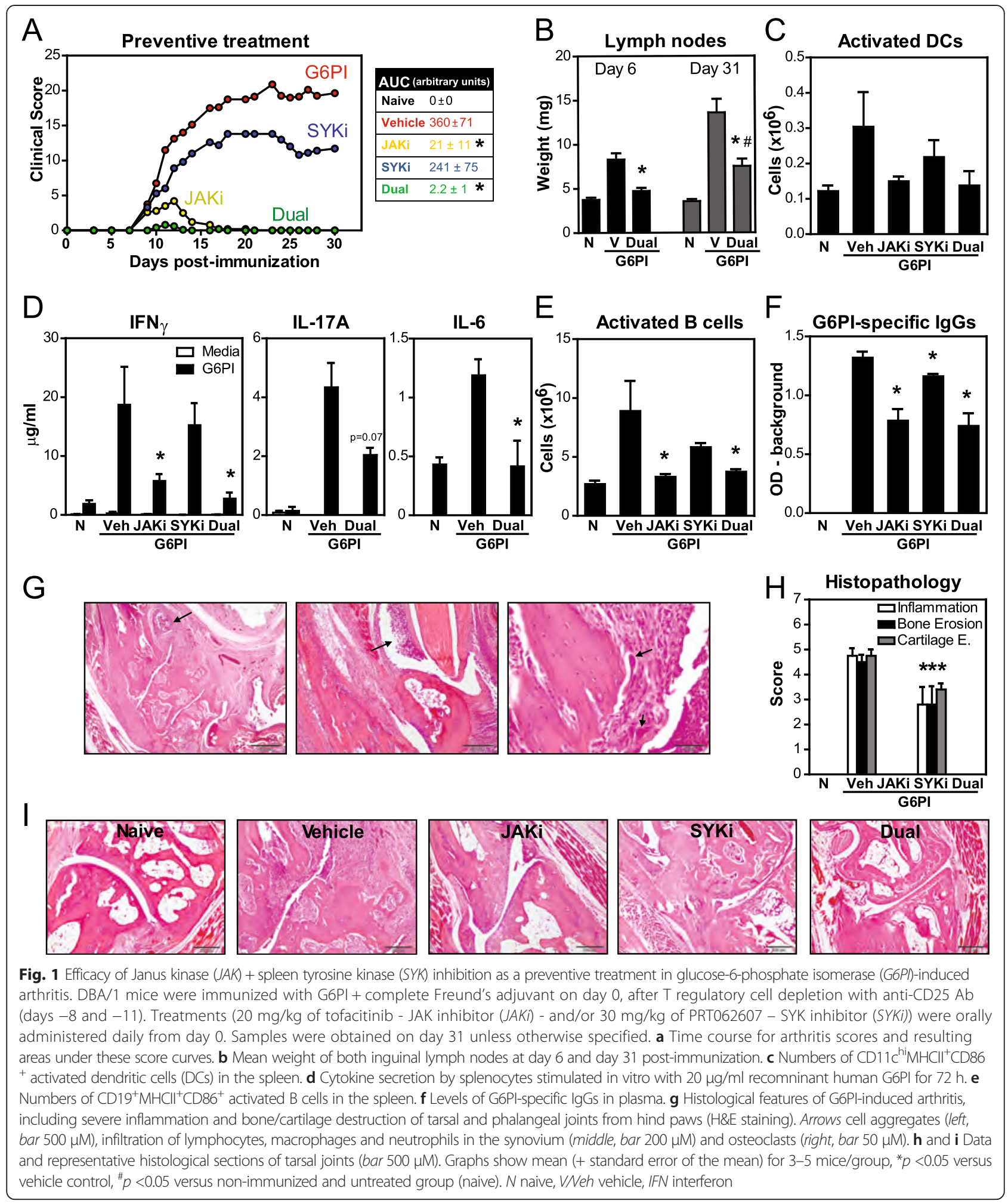

with JAKi + SYKi, likely contributing to minimize antigenspecific immune responses.

Parameters of T and B cell activity support a critical role for JAK signaling in the induction phase of the disease.
Splenocytes from treated mice were stimulated in vitro with G6PI for $72 \mathrm{~h}$ and cytokine production was quantified by ELISA. Levels of IFN $\gamma$, IL-17A and IL- 6 were comparable in vehicle controls and SYKi-treated mice (Fig. 1d 
and not shown). In contrast, JAKi decreased cytokine production and a greater reduction was observed upon dual JAKi + SYKi, confirming milder Th1/Th17 responses in these groups. Similarly, CD86 ${ }^{+}$-activated B cells and levels of G6PI-specific IgGs were significantly lower in mice receiving JAKi or JAKi + SYKi (Fig. 1e and f).

A detailed histopathological evaluation of the hind limbs of arthritic mice revealed severe lesions in both tarsal (Fig. 1g-i) and phalangeal (not shown) joints with abundant immune and inflammatory cells (primarily lymphocytes, macrophages and neutrophils), pannus formation with neovascularization, marked cartilage and bone erosion, loss of trabeculae and presence of more fibroblasts and osteoclasts. Dual JAK + SYK inhibition prevented paw inflammation and bone/cartilage damage. Most of these effects were driven by JAK inhibition, which completely cleared an initial mild inflammatory response and prevented bone and cartilage erosion. With SYKi the histopathology score was reduced by $30-40 \%$ at day 31 .

Dual JAK + SYK inhibition ameliorates chronic and severe G6PI-induced arthritis

We next evaluated the therapeutic potential of dual JAK + SYK inhibition in a curative protocol, which is a more strenuous measure of activity and is clinically more relevant. In this case, oral daily treatment was started at day 12 post-immunization, when clinical signs, primarily inflammation in proximal and distal joints of paws, were present. The clinical score of vehicle control mice progressively increased, becoming stable around day 20 (Fig. 2a). Inhibition of JAK, but not SYK, was able to stop disease progression, and after 2 weeks of treatment started to mildly reduce arthritis severity. By day 31 , mice treated with JAKi or prednisolone (3 $\mathrm{mg} / \mathrm{kg}$ QD), a corticosteroid

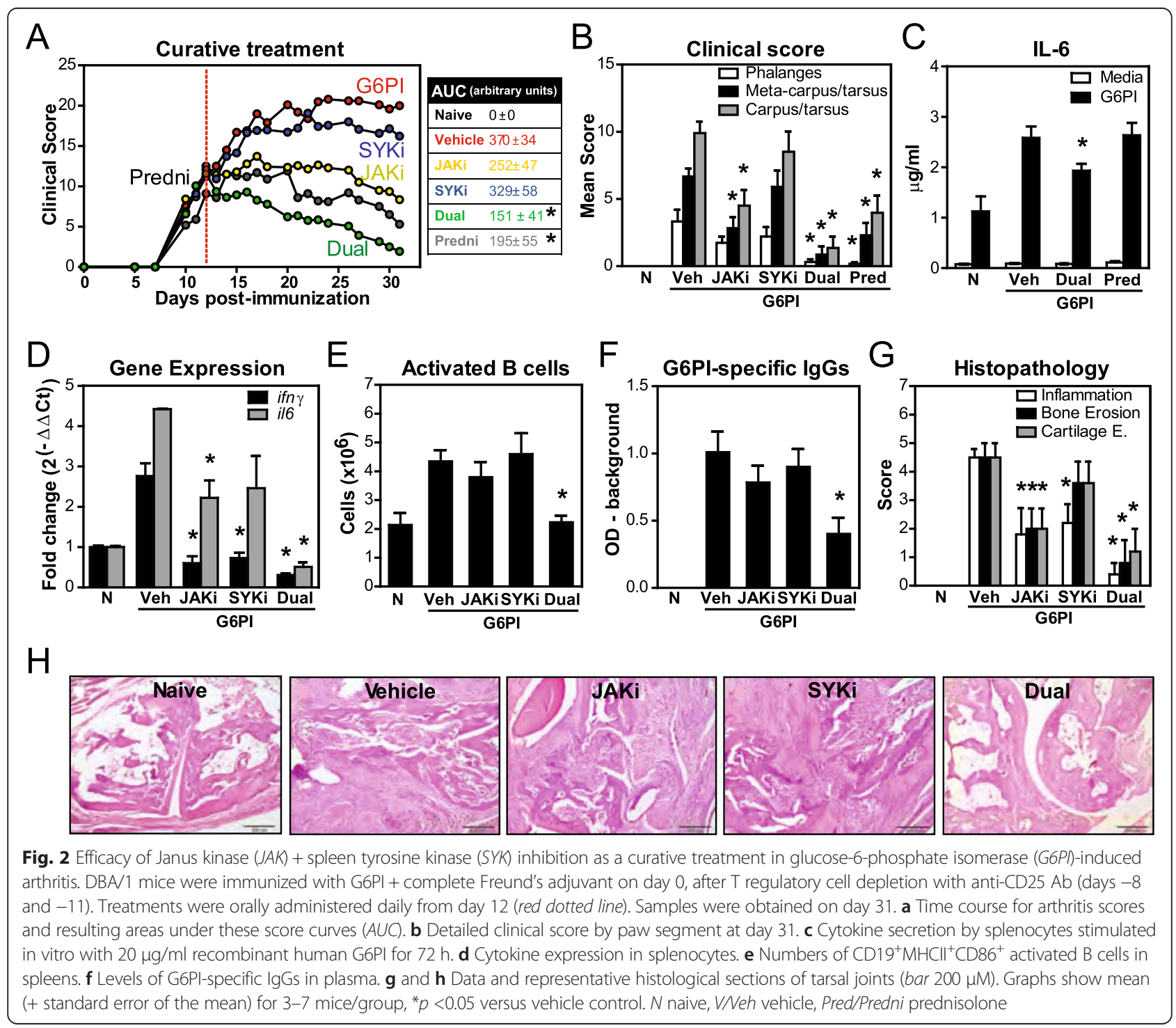


widely used as anti-inflammatory agent, had a reduction in overall clinical score of $58 \%$ and $74 \%$, respectively. In contrast, dual JAKi + SYKi immediately prompted a gradual decrease in the clinical score for all joints (Fig. 2b) from all mice and over $70 \%$ of these mice were totally cured (score of 0 ) after 3 weeks of treatment.

Upon in vitro G6PI stimulation of splenocytes from these mice, IL-6 production was only significantly reduced in the dual treatment group (Fig. 2c), confirming attenuation on antigen-specific responses. Th1 (IFNY) and Th17 (IL-17A and IL-6) cytokine expression was also decreased (Fig. 2d and not shown). Furthermore, combined JAKi + SYKi was more effective at limiting $B$ cell activation and function, as assessed by the levels of serum G6PI-specific IgG, relative to either inhibitor alone (Fig. 2e and f).
In terms of histopathological changes in tarsal joints (Fig. $2 \mathrm{~g}$ and h), single JAKi or SYKi decreased around $50 \%$ of joint inflammation, while dual treatment induced a reduction of over $90 \%$. Of interest, only simultaneous inhibition of JAK + SYK was able to prevent bone and cartilage damage, showing a completely normal joint structure in $60 \%$ of mice. Therefore, concurrent JAK + SYK inhibition ameliorates clinical, immunological and histological parameters of arthritis.

\section{Dual JAK + SYK inhibition is more effective than anti-TNF} treatment

We have showed greater efficacy of dual versus single JAK and SYK inhibition in a chronic model of arthritis.
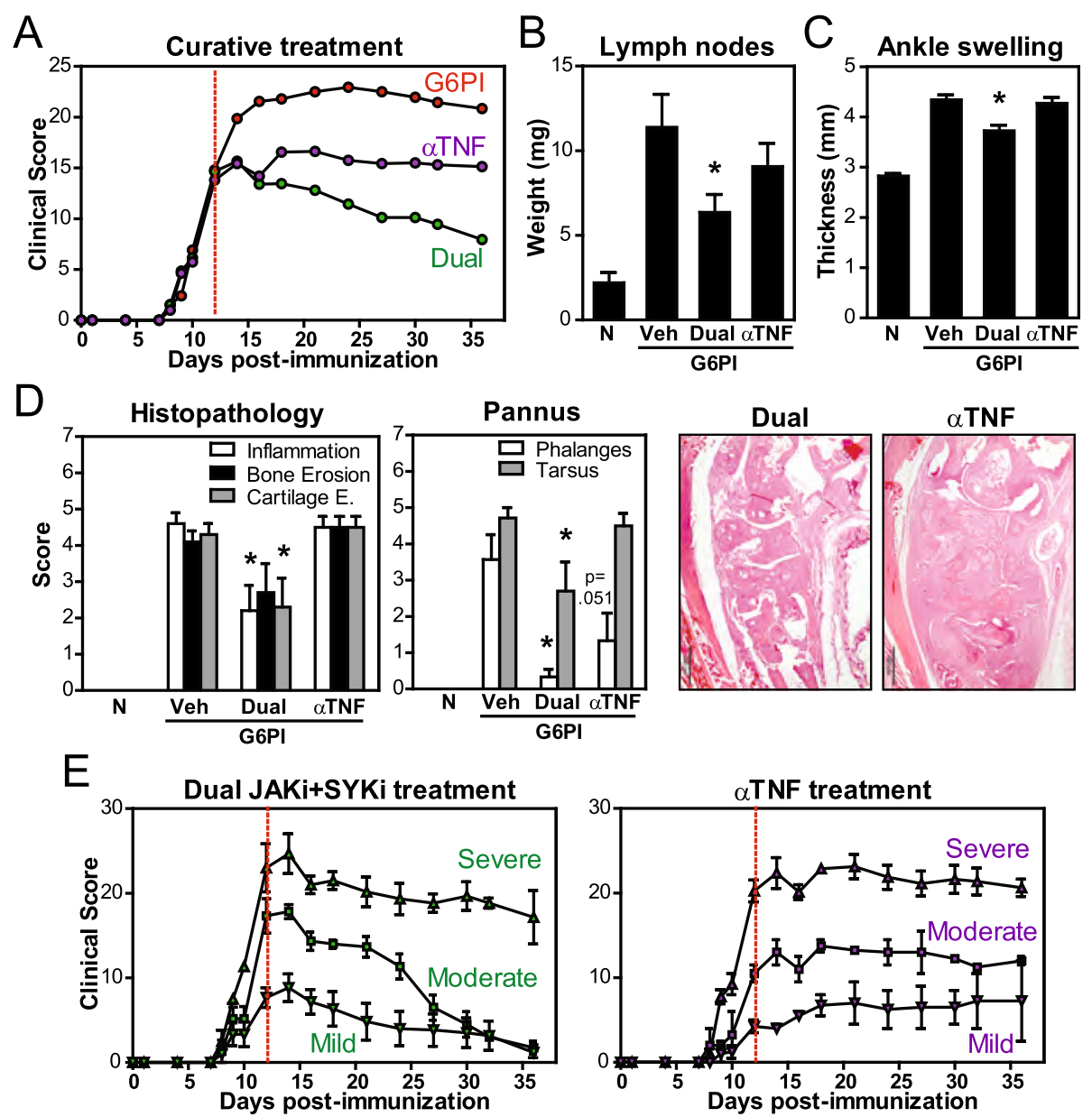

Fig. 3 Therapeutic comparison of Janus kinase (JAK) + spleen tyrosine kinase (SYK) inhibition and anti-TNF therapy in glucose-6-phosphate isomerase (G6PI)-induced arthritis. DBA/1 mice were immunized with G6PI + complete Freund's adjuvant on day 0, after T regulatory cell depletion with anti-CD25 Ab (days -8 and -11). Treatments were administered starting on day 12 (red dotted line). Samples were obtained on day 36. a Time course for arthritis scores. $\mathbf{b}$ Mean weight of both inguinal lymph nodes. $\mathbf{c}$ Mean ankle thickness of both hind paws measured with a manual caliper. $\mathbf{d}$ Histopathological scores for tarsus and pannus formation in both phalanges and tarsus. Representative histological sections of tarsal joints are also shown (bar $500 \mu \mathrm{M})$. e Time course for arthritis scores for mice with mild, moderate and severe arthritis at the time of treatment initiation. Graphs show mean ( \pm standard error of the mean) for 2-10 mice/group, ${ }^{*} p<0.05$ versus vehicle control. $N$ naive, Veh vehicle 
Next, we compared the efficacy of dual JAKi + SYKi with anti-TNF therapy, a standard anti-rheumatic biological approach used in the clinics. Previous reports showed that anti-TNF prevents the development of very early acute G6PI arthritis [20, 26]. Here, we started treatment of Treg-depleted G6PI immunized mice when arthritic symptoms were moderate to severe. Interestingly, both TNF blockade (10 mg/kg, every third day) and dual JAKi + SYKi stopped disease worsening but only dual treatment was able to progressively decrease the clinical score, which had decreased by over $60 \%$ at the endpoint (Fig. 3a). The average area under the clinical score curve decreased by $42 \%$ with dual treatment, while it only decreased by $25 \%$ with etanercept (not shown). Accordingly, lymph node weight (Fig. 3b) and ankle thickness (Fig. 3c) were significantly lower in all mice treated with JAKi + SYKi but not with anti-TNF. Moreover, $66 \%$ of dual-treated mice experienced complete recovery of phalangeal joints after 3 weeks of treatment (not shown). Blinded histologic observations also confirmed reduced recruitment of immune and inflammatory cells and joint damage in tarsal joints of mice treated with JAKi + SYKi but not in anti-TNFtreated mice (Fig. 3d). Abnormal layers of granulation and fibrovascular tissue (pannus) were abundant in joints of vehicle-treated mice, which coincides with chronic and severe stages of arthritis. Dual inhibition significantly reduced pannus progression in both tarsal and phalangeal joints, while anti-TNF treatment only had a partial effect in phalanges. Furthermore, Fig. 3e shows that dual kinase inhibition reversed the pathological changes in mice with mild and moderate disease and decreased symptoms in mice with very severe disease. In contrast, blockade of TNF stopped, without improving, disease progression in all groups. Thus, dual JAK + SYK inhibition also presents greater efficacy than anti-TNF treatment in this experimental model of severe arthritis.

\section{Evaluation of potential immunotoxicity of dual JAK + SYK inhibition}

We next evaluated whether the benefit of greater efficacy of dual JAKi + SYKi in arthritis was limited by increased adverse effects imputable to target inhibition. To this end, mouse weight as well as hematological and immunological parameters were examined in mice immunized either with G6PI + CFA (Figs. 4a-c and 5a) or with KLH (Fig. 4d-f) and treated for extended periods of time, i.e., 3 or 4 weeks, respectively. KLH is an immunogen routinely used in the rodent TDAR model, which allows detection of potential immunotoxicity, especially immunosuppression. As shown in Additional file 3a and $\mathrm{b}$, the body weight from mice treated with JAKi/SYKi remained comparable to vehicle-treated animals. As expected, the control immunosuppressant drug prednisolone significantly reduced body weight, circulating white blood cells, spleen weight and both $\mathrm{CD}^{+} \mathrm{T}$ cell and B cell counts in G6PI- and KLH-immunized mice. Kinase inhibitors alone or in combination and anti-TNF treatment did not alter red blood cell or white blood cell numbers. Dual JAKi + SYKi and single JAKi decreased spleen weight compared to G6PI-immunized controls but never below naive levels, and without affecting CD4 ${ }^{+}{ }^{+}$cell and B cell counts. In the TDAR model, dual JAK + SYK inhibition, but not etanercept, decreased B cell counts but never below baseline, and consequently, KLH-specific antibody production was also only mildly reduced.

Preclinical studies and clinical trials with tofacitinib have highlighted an impact on Treg cells. Here, we also observed a significant decrease in Treg counts in the spleen of mice treated with tofacitinib and, consequently, also with dual JAKi + SYKi, but not SYKi alone (Fig. 5a). Similar diminished Treg numbers were identified in prednisolone-treated mice.

We also examined potential effects of JAKi, SYKi and TNF blockade on cytotoxic cell populations (Fig. 5a). $\mathrm{CD} 8^{+} \mathrm{T}$ cell counts were similar in all groups. In contrast, dual inhibition, but not anti-TNF (not shown) significantly impacted on natural killer (NK) cell numbers, likely due to a direct effect of JAK inhibition on IL-15 signaling. Under these conditions, we observed a fully functional cell-mediated cytotoxic response of in vivo treated splenocytes on target YAC-1 cells upon coculture (Fig. 5b left). Comparable results were obtained in another cytotoxic assay with murine splenocytes from naive mice but, this time, treated in vitro with physiologically relevant $(0.5 \mu \mathrm{M})$, and ten times higher $(5 \mu \mathrm{M})$, concentrations (Fig. 5b right). Therefore, reduced NK cell numbers upon dual inhibition did not impact overall cytotoxic activity. In a separate experiment, we confirmed that tofacitinib and PRT062607 were not cytotoxic at the assayed doses (Additional file $3 C)$.

In terms of potential effects on the phagocytic cell compartment, human PBMCs showed intact phagocytosis of Escherichia coli bioparticles when exposed to $0.5 \mu \mathrm{M}$ of JAKi and/or SYKi for $1 \mathrm{~h}$ (Fig. 5c). At the high concentration of $5 \mu \mathrm{M}$, dual inhibition decreased almost $60 \%$ the phagocytic activity of PBMCs, which can be explained by the role of SYK on actin cytoskeleton reorganization during phagocytic vesicle closure. The flow cytometric analysis revealed $\mathrm{CD} 14^{+}$cells and granulocytes to be the main phagocytes involved. Again, these adverse effects have a limited impact in vivo, as high plasmatic concentrations are reached only for short periods of time. Overall, our data show that dual JAK + SYK inhibition is efficacious and has a good safety profile, and therefore can be seen as a candidate treatment strategy in arthritis. 


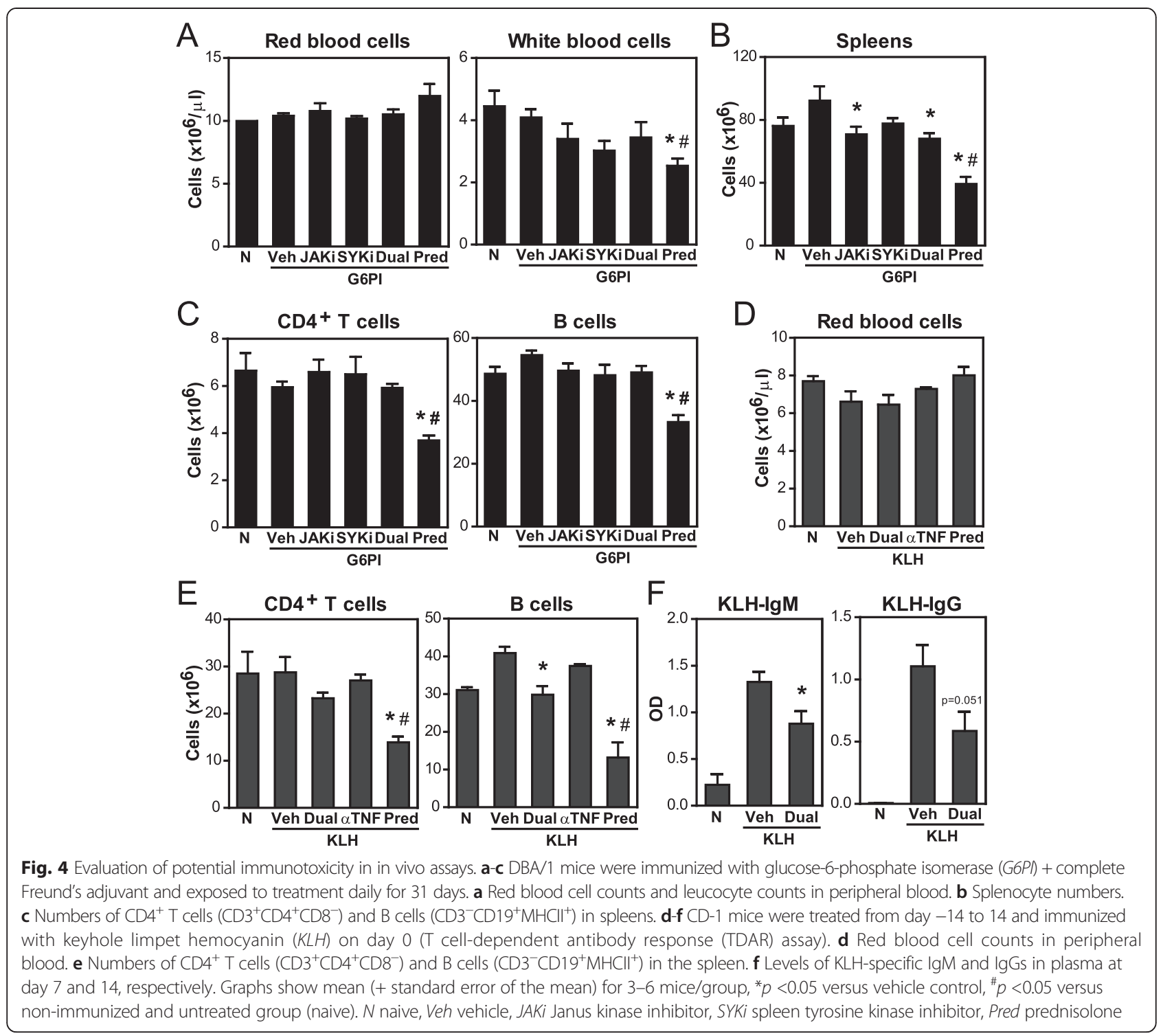

\section{Sustained efficacy and reversed adverse effects after} discontinuation of dual treatment

We next stopped treatment and ten days later $75 \%$ of arthritic mice treated with both inhibitors either maintained or continued to ameliorate clinical signs (Fig. 5d). In sharp contrast, discontinuation of anti-TNF treatment led to a worsening of paw inflammation in all mice. Indeed, an average $17 \%$ increase in the clinical score was observed in this group, reaching a score comparable to vehicle-treated arthritic mice. Therefore, the benefits of dual JAK + SYK inhibition were perpetuated longer than anti-TNF. Therapy discontinuation also led to immune recovery. The reduced Treg and NK cell counts after daily JAKi + SYKi were quickly restored to normal levels (Fig. 5e), which minimizes potential adverse effects.
Dual JAK + SYK inhibition impacts the development and function of synoviocytes and osteoclasts

Resident cells of the joint are major contributors to arthritis pathology. In particular, FLS and osteoclasts represent a link between joint inflammation and structural damage, which is critical in the functional disability of RA patients. Here, we studied the importance of the JAK and SYK pathways on their function in order to understand the mechanism leading to increased efficacy of dual JAKi + SYKi. FLS were isolated from small joints of mice with chronic arthritis (Treg-depleted). Stimulation of FLS with TNF and IL-17A, which are elevated in arthritic mice (Fig. 1 and Additional file 2) and in the synovium of RA patients [27, 28], induced IL-6 and MMP production (Fig. 6a). Dual JAKi + SYKi markedly 


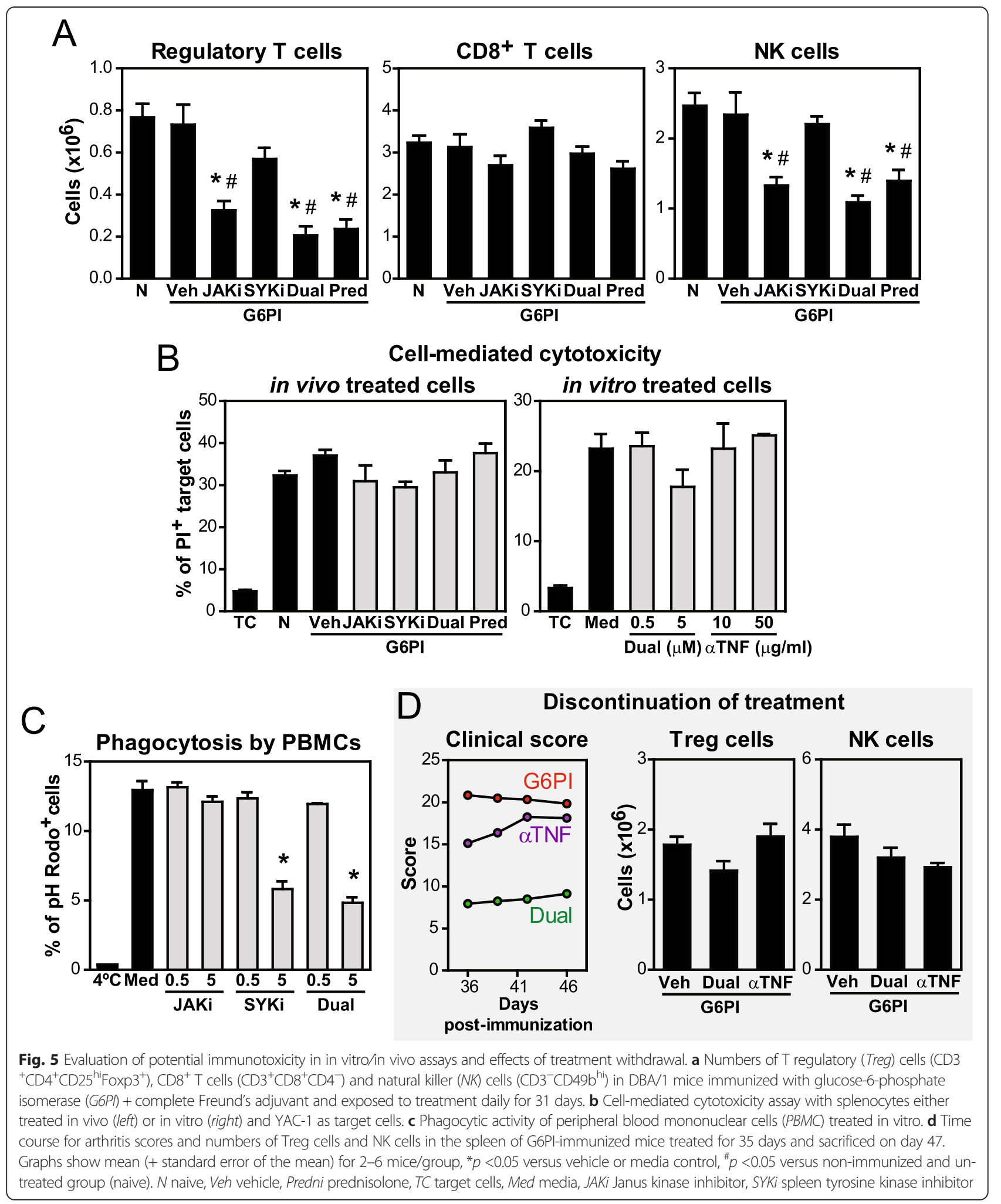

reduced IL-6 secretion to a similar extent to JAKi. Milder effects were observed in MMP9 and MMP3 levels (not shown). In a transwell system with collagen-coated inserts, JAKi, SYKi and dual JAKi + SYKi decreased the invasive capacity of FLS by 13, 27 and $50 \%$, respectively (Fig. 6b). Therefore, JAK mediated cytokine production, and both JAK and SYK additively contributed to collagen invasiveness, a critical step in cartilage destruction. 


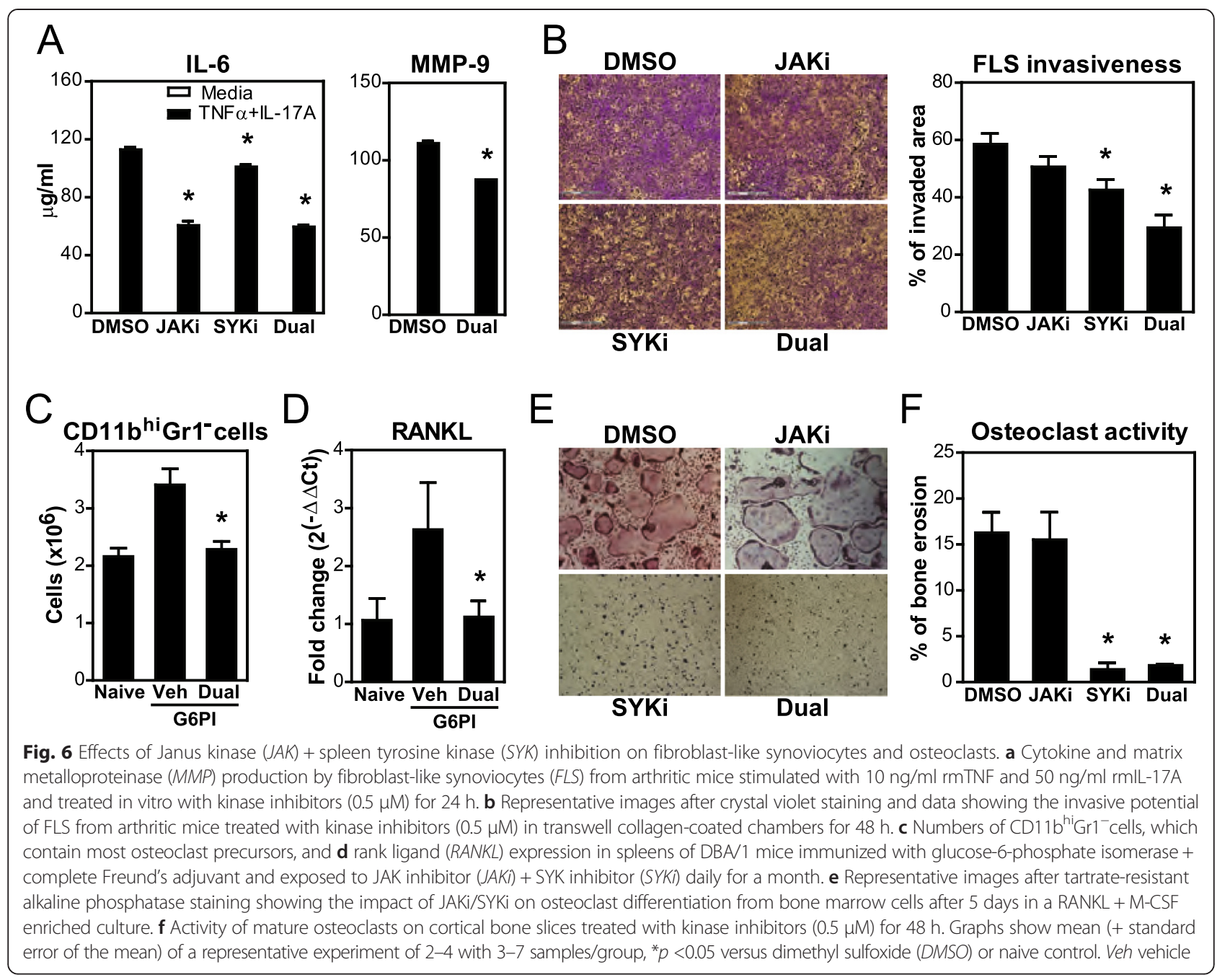

In bone destruction, osteoclasts are the primary resorbing cells. Here, we found that G6PI-immunized mice treated with JAKi + SYKi had baseline counts of osteoclast precursors $\left(\mathrm{CD} 11 \mathrm{~b}^{\mathrm{hi}} \mathrm{Gr} 1^{-}\right.$cells) and levels of RANKL expression in spleens (Fig. 6c and d). Furthermore, in vitro osteoclastogenesis from bone marrow cells was completely prevented with SYKi and dual JAKi + SYKi exposure (Fig. 6e). We also exposed mature osteoclasts to these inhibitors and observed that SYK, but not JAK, is critically required for bone resorption activity (Fig. 6f). Thus, dual JAKi + SYKi treatment interferes at multiple stages in osteoclast development and function, primarily via SYK.

Dual JAK + SYK inhibition also regulates effector and memory $\mathrm{CD}^{+} \mathrm{T}$ cells and plasma cells

The JAK/STAT pathway is known to mediate $\mathrm{T}$ cell differentiation by interfering with cytokine signaling. Our data show that dual JAKi + SYKi prevented T cell proliferation upon unspecific stimulation in vitro (Fig. 7a). Antigen- specific responses, primarily IFN $\gamma$ and IL-6 production, were also markedly decreased in splenocytes from arthritic mice treated in vitro with both inhibitors (Fig. 7b).

Cells of the immunological memory, in particular memory $\mathrm{T}$ cells and long-lived plasma cells are implicated in the chronification of disease and have proven to be refractory to conventional immunosuppression [29]. In order to investigate the role of JAK and SYK on memory cell maintenance, OVA-immunized mice were treated with inhibitors starting 2 weeks after challenge, a time when memory cells are already generated. The number of memory $\mathrm{CD} 4^{+} \mathrm{CD} 44^{\text {hi }} \mathrm{T}$ cells was similarly decreased in mice treated with JAKi and dual JAKi + SYKi (Fig. 7c). Upon OVA re-exposure in vitro, JAKi + SYKi markedly reduced antigen-specific $\left(\mathrm{CD}_{40 \mathrm{~L}^{+}}\right) \mathrm{CD} 4^{+} \mathrm{T}$ cells and their ability to produce IFN $\gamma$, IL-2 and TNFa (Fig. $7 \mathrm{~d}$ and e). OVA-specific memory plasma cells $\left(\mathrm{CD} 138^{+} \kappa \lambda^{\text {hi }}\right)$ were also significantly reduced by an additive effect on JAK and SYK signaling (Fig. 7f). Thus, both JAK and SYK mediate memory cell pool maintenance and, thus, their 


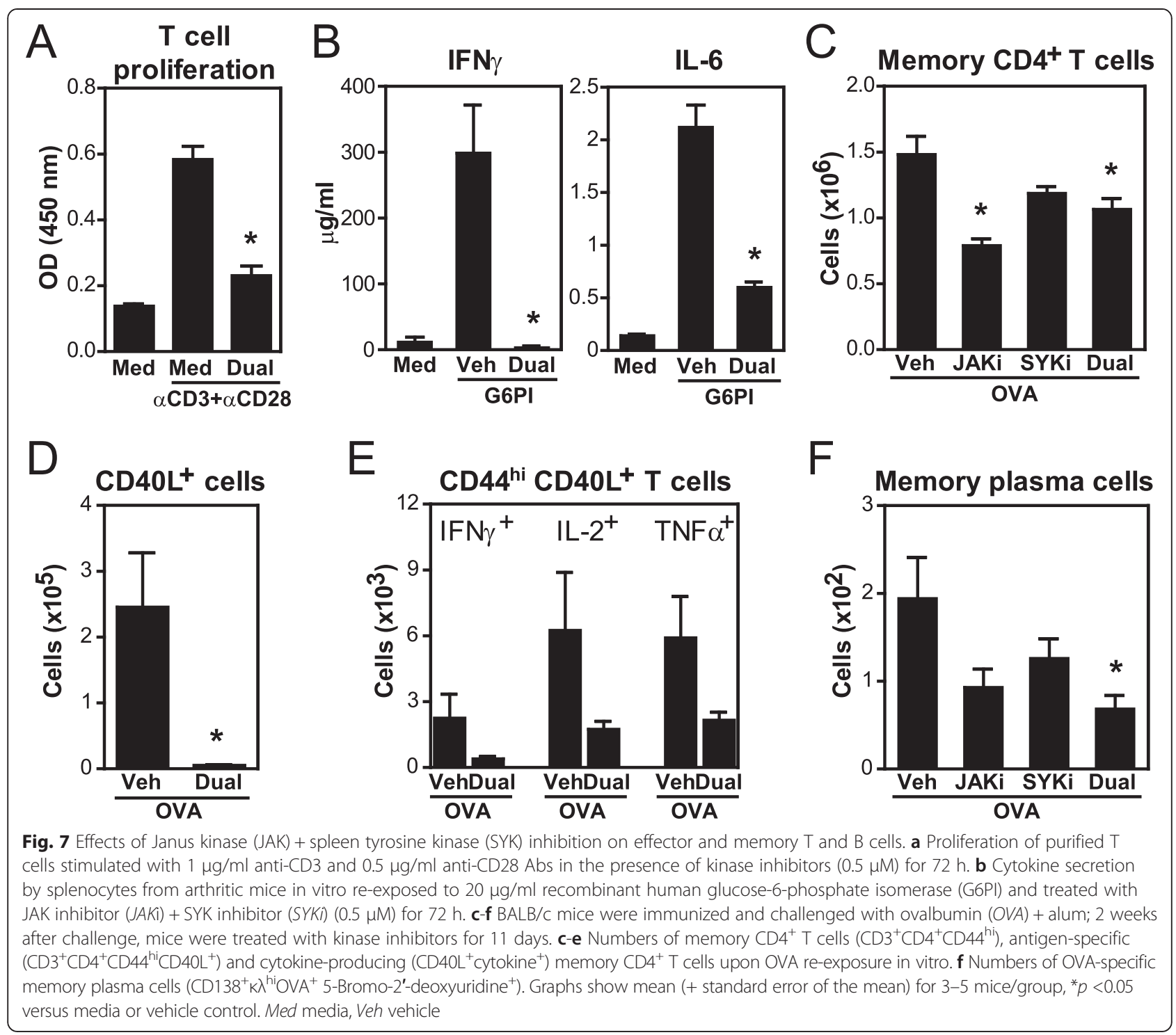

inhibition could maintain disease remission and prevent arthritis recurrence.

\section{Discussion}

Tofacitinib has demonstrated high efficacy in phase II and III trials and even in patients not responding to current treatments. However, the response is limited (ACR20 48-51 \%) [12, 13], so there are still difficult-totreat patients with RA in need of new therapeutic approaches. To our knowledge, no clinical trial has evaluated the potential benefits of a selective SYK inhibitor in RA patients. Here, we studied whether the addition of a SYK inhibitor into a JAK inhibition therapy could improve the efficacy achieved by single inhibition. We used the murine Treg-depleted G6PI-induced arthritis model, a clinically relevant model characterized by non-remitting and progressive peripheral polyarthritis with loss of joint structure and function [21].

In a preventive protocol, our data clearly show that combined JAKi + SYKi offers greater prophylactic efficacy than single kinase inhibition (Fig. 1). Mice treated with JAKi alone had very mild disease that completely resolved within 2 weeks. At study termination, there were no signs of inflammation and joint morphology looked normal. These results can be in part explained by the importance of JAK on Th cell differentiation and function [30], and the critical role of CD4 ${ }^{+} \mathrm{T}$ cells in the induction phase of this chronic G6PI model [21] and others [31]. Here, we found that antigen-specific $\mathrm{T}$ cell responses were similarly reduced in JAKi- and JAKi + SYKi-treated mice. Inhibition of JAKs also reduced the number of activated DCs. Recent reports show that JAK inhibition profoundly modulates DC development and 
activation, which is most likely due to signaling blockade of the critical differentiating signals GM-CSF and IL-4 [32-34]. In this scenario of reduced $\mathrm{DC}$ and $\mathrm{T}$ cell activation, it is not surprising to see lower numbers of activated B cells and G6PI-specific IgGs upon JAK inhibition. Single inhibition of SYK led to the development of milder arthritis. A greater role for SYK on disease induction has been reported in other models; in particular, genetic deficiency of Syk in the hematopoietic compartment completely blocked the development of arthritis in the K/ BxN serum-transfer murine model [35] and Coffey et al. [19] reported PRT062607 to dose-dependently reduce the development of paw inflammation in a murine CAIA model. While greater doses of SYKi could be administered to likely enhance efficacy, we did not want to compromise kinase selectivity. Mice treated with SYKi had decreased numbers of activated DCs, B cells and IgG levels, likely explained by the role of SYK on B cell receptor (BCR) signaling and DC maturation via $C$ type lectin receptors [36]. Thus, both JAK and SYK signaling pathways are involved in early pathogenic mechanisms of arthritis and simultaneous inhibition of both kinases results in greater efficacy.

We also followed a curative protocol (Fig. 2), in which treatment was started at day 12 post-immunization, when clinical signs were clearly present and affected multiple joints. Under these conditions, inhibition of SYK resulted in a minimal (non-significant) decrease of arthritis parameters. Our results are in contrast with a previous preclinical study in the rat CIA model showing significant efficacy of PRT062607 when treatment was initiated early, i.e., when at least one hind paw showed first signs of inflammation (score 1) [19]. These differences in efficacy may result from using distinct experimental models (CIA in rat is acute and less stringent) and starting treatment at different disease stages (mild versus moderate). Inhibition of JAK immediately stopped disease worsening and started to ameliorate clinical signs after 2 weeks of daily treatment, ending with moderate disease. These results parallel the responses of arthritic patients to tofacitinib, i.e., significant clinical and physical improvement as early as 2 weeks and inhibition of progress in joint destruction after 6 months of treatment $[9,12,14]$. This lower efficacy of JAKi in the curative protocol compared to the preventive one can be partially explained by the reduced importance of effector $\mathrm{CD}_{4}^{+} \mathrm{T}$ cells when disease is already established. Indeed, Frey et al. [21] reported that the effector phase of arthritis in the Treg-depleted G6PI model is non-dependent on CD4 ${ }^{+} \mathrm{T}$ cells, when other cell populations, such as phagocytes, are more relevant. If multiple local cells of the joint, rather than adaptive immune cells, drive disease progression during the effector phase of arthritis, it is not surprising to see that therapeutically targeting two signaling pathways is more effective than targeting only one. Indeed, the observed changes after dual JAKi + SYKi were impressive, with no symptoms to minimal symptoms at study termination. In fact, dual inhibition decreased clinical scores in all mice with distinct degrees of arthritis severity, showing $87 \%, 90 \%$ and $30 \%$ reduction in mild, moderate and severe arthritis, respectively (Fig. 3d).

To further support this notion of broader amelioration with multi-pathway inhibition, dual JAKi + SYKi also resulted in higher efficacy than anti-TNF therapy, the most common first choice biologic strategy (ACR guidelines 2012) (Fig. 3). Blockade of TNF with etanercept stopped, without improving, disease progression in mice with mild, moderate and severe arthritis, resulting in an average clinical score $25 \%$ lower than vehicle-treated mice, but 39 \% higher than dual treatment. Furthermore, partial arthritis amelioration after etanercept treatment was only observed in phalangeal joints, as tarsus remained with maximal inflammatory infiltrates, pannus and severe bone/cartilage erosion. To confirm the activity of the drug used, we found that etanercept was able to prevent disease onset in CIA mice (not shown). Thus, targeting only one pro-inflammatory signal when severe and erosive disease is already established results in reduced and slower recovery than dual JAKi + SYKi treatment. The observed partial efficacy of TNF blockade under these severe conditions is not surprising, as $30-40 \%$ of RA patients have an inadequate response to TNF inhibitors [37-39]. The increased efficacy of our proposed mechanism of action in this demanding model of arthritis, in which other therapies fail, suggests JAKi + SYKi as a potential pharmacological tool to treat patients not responding to current treatments. Our data also endorse the use of the chronic G6PI model to investigate difficult-to-treat arthritis.

The benefits of dual JAKi + SYKi need to be considered in the context of the risks of adverse events. The most common target-related adverse effects observed in clinical trials with JAK include a higher incidence of infection (resulting from immunosuppression) and anemia [14]. Of note, companies have minimized or overcome some adverse events by optimizing the dose and posology. Our data revealed that a month of daily treatment with JAKi + SYKi did not reduce total circulating leucocytes or red blood cell counts, hemoglobin or hematocrit levels in arthritic (Fig. 4) and healthy KLH-immunized mice (not shown). The weight and cellularity (not shown) of spleens and lymph nodes were decreased but never below those from naive mice or those treated with prednisolone, a well-known immunosuppressive agent. A phenotypic analysis in the spleen revealed no significant changes on $\mathrm{CD}^{+} \mathrm{T}$ or $\mathrm{B}$ cell counts in all treated arthritic mice, albeit $\mathrm{B}$ cells were reduced to baseline numbers in KLH-immunized mice. Such reduction was paralleled by lower KLH-specific IgG production, which 
is consistent with the observed reduction in the levels of G6PI-specific IgG (Fig. 1). Importantly for host defense against pathogens, the ability to generate antibodies was never completely abolished by single or dual treatment, allowing these treated mice to still mount robust antigen-specific humoral responses. A study in monkeys also reported none to modest effects on leucocytes, $\mathrm{T}$ and B cell counts after chronic (3-week), oral tofacitinib administration [40]. In contrast, mice deficient on JAK3 $\left(\mathrm{JAK}^{-/-}\right)$, common $\gamma \mathrm{c}\left(\mathrm{\gamma c}^{-/-}\right)$or receiving tofacitinib by infusion with osmotic minipumps showed marked reductions in $\mathrm{T}$ and $\mathrm{B}$ cell numbers [41-44]. These suggest that intermittent, rather than continuous, kinase inhibition reduces immunosuppression without compromising efficacy.

Non-specific defense mechanisms, including cytotoxicity and phagocytosis, were also preserved in mice exposed to physiologically relevant concentrations of JAKi + SYKi (Fig. 5). Numbers of $\mathrm{CD}^{+} \mathrm{T}$ cells and neutrophils (not shown) were comparable among healthy and treated mice. In contrast, NK cell counts significantly decreased $43 \%$ and $53 \%$ after chronic JAKi or JAKi + SYKi, respectively. This selective effect on NK cells was already observed after 6 days of treatment (not shown) and is in accordance with the reported time- and dose-dependent reduction of circulating NK cells after tofacitinib administration [40]. $\mathrm{JAK}^{-/-}$and $\mathrm{\gamma c}^{-/-}$mice also exhibited a profound loss of NK cells [44], which is consistent with the known role of IL-15 and IL-21 for their homeostasis [45]. Importantly, a reduction only in this population was not sufficient to impact overall cytotoxicity. After chronic treatment with dual JAKi + SYKi, the number of $\mathrm{CD}^{+} \mathrm{CD} 4^{+} \mathrm{CD} 25^{\text {bright }} \mathrm{Foxp}^{+} \mathrm{T}$ cells (Treg) decreased $70 \%$ from baseline. A comparable decrease was observed in mice treated with JAKi, which could be explained by the critical requirement of IL-2/ JAK1\&3/STAT5 signaling for the maturation of FOXP3 ${ }^{+}$ Tregs $[46,47]$. Decreased Treg counts after chronic tofacitinib administration has been reported by others that further demonstrate that the regulatory capacities of the residual Treg cells remain normal [48]. Collectively, our data show that the potential target-related adverse effects of dual inhibition do not increase compared to each single inhibition and are mitigated because we managed to transiently inhibit JAK and SYK signaling. In particular, 6-12 h compound coverage (Additional file 1) was sufficient to ameliorate the disease in this model and allow enough time for most basic physiological processes to recover homeostasis.

It is important for safety and economic reasons to consider the possibility of therapy withdrawal. Here we show that the significant reduction in Treg and NK cell counts in mice chronically exposed to JAKi + SYKi was quickly reversed after treatment discontinuation (Fig. 5).
Interestingly, the clinical score of these mice remained low, suggesting long-lasting effects of dual treatment. In sharp contrast, discontinuation of anti-TNF treatment led to a prompt rebound of disease, i.e., clinical scores reached arthritic control severity in less than a week. Thus, the specific immune suppression resulting from dual JAKi + SYKi treatment can be easily reversed without compromising efficacy. Further studies should determine the optimal treatment regimen to preserve the clinical benefit, avoid disease recurrence and reduce adverse events.

In order to understand the mechanism leading to increased efficacy by dual JAKi + SYKi, we studied the contribution of these kinase pathways on specific cell subsets relevant to disease pathology (Figs. 6 and 7). Local FLS and osteoclasts are major effectors of joint inflammation (synovitis) and destruction, and therefore are important therapeutic targets in RA. Our data show that JAKi + SYKi significantly reduced the aggressive phenotype of arthritic FLS (Fig. 6a and b). Interestingly, cytokine production upon TNF + IL-17A stimulation was primarily JAK-dependent, while SYK signaling contributed more to FLS invasiveness. In this regard, the JAK-STAT pathway has been implicated in TNF and IL17 signaling via autocrine production of IFN $\beta$ and PI3K activation, respectively [49-51]; and SYK is involved in the signaling of integrins that mediate FLS adhesion and invasion to the extracellular matrix, an important initiating step in the progressive destruction of articular cartilage (reviewed in [52, 53]). Dual JAKi + SYKi also prevented extensive bone destruction by altering both osteoclastogenesis and osteoclast activity (Fig. 6c-f). In particular, we found that mice treated with JAKi + SYKi had fewer $\mathrm{CD} 11 \mathrm{~b}^{\mathrm{hi}} \mathrm{Gr}^{-/ l o}$ splenocytes, a population with osteoclast-forming potential; in fact, $60-70 \%$ of these cells are known to differentiate into $\mathrm{TRAP}^{+}$osteoclasts when cultured with RANKL and M-CSF $[54,55]$. Dual JAKi + SYKi, solely via SYKi, completely blocked intercellular fusion and bone erosion activity but osteoclasts still showed partial TRAP activity (not shown). This is in accordance with $\mathrm{syk}^{-/-}$osteoclasts, which do not differentiate morphologically but still express mature osteoclast markers, and also show impaired functional resorption of mineralized matrix [18]. These alterations are likely explained by the importance of SYK on cytoskeletal rearrangements and specific integrin-mediated functions (reviewed in [56, 57]. These in vitro results along with our histopathological data from arthritic mice (Fig. $2 \mathrm{~g}$ ) reinforce the idea that affecting multiple cell types with dual inhibition is more effective than single inhibition in this complex system.

There are a growing number of reports pointing to the importance of chronically activated synovial $\mathrm{T}$ cells for the stimulation of resident FLS and osteoclast precursors. Our 
data show that dual JAKi + SYKi markedly reduced $\mathrm{T}$ cell proliferation and cytokine production upon unspecific stimulation or antigen re-exposure, suggesting a counteracting effect on aberrant $\mathrm{T}$ cell activity (Fig. 7). It is likely that this effect was IL-2 driven, and, thus, more dependent on JAK. RANKL expression, primarily found on $\mathrm{T}$ cells but also B cells and FLS [58, 59], was also significantly lower in JAKi + SYKi-treated mice, which further contributes to decreasing osteoclast differentiation and activity. $\mathrm{T}$ and $\mathrm{B}$ cells have been suggested to also play a key role in the perpetuation and recurrence of symptoms, in part due to the generation of immunological memory. Therefore, combating autoimmune memory, yet a challenge, is seen as an important clinical goal. Here, our data show that the memory $\mathrm{CD} 4^{+} \mathrm{T}$ cell pool and, to a greater extent, the antigen-specific effector subset were significantly reduced after JAKi + SYKi treatment. As treatment was started 2 weeks after antigen challenge, a time when memory cells are already generated $[60,61]$, our data suggest an effect of JAKi on memory $\mathrm{T}$ cell maintenance. In this regard, IL-7 is known to be critical for memory CD4 cell survival [62], and IL-7 signals via the JAK1/JAK3-STAT5 pathway. Dual treatment also reduced the number of antigen-specific memory plasma cells $\left(\mathrm{CD} 138^{+} \mathrm{K} \lambda^{\mathrm{hi}}\right)$. While the factors involved in plasma cell survival are poorly understood, we speculate that blockade of IL-6 signaling via the JAK1-STAT3 pathway, and perhaps B cell activating factor (BAFF) responsiveness, which has recently been shown to require SYK, may explain the reduced memory plasma cell counts $[63,64]$.

RA initiates many years before clinical onset, which raises the demands for prevention and early diagnosis. Our data suggest simultaneous inhibition of JAK + SYK to be a very efficacious treatment strategy at early stages of disease development, as it interferes with multiple steps of the immunization process, i.e., activation of DCs, B cells and T cells. Our work also shows that dual inhibition is more effective than current therapeutic strategies, namely anti-TNF or single JAKi, in ameliorating severe disease manifestations. Paw inflammation, bone erosion and cartilage damage were significantly reduced in mice treated with JAKi + SYKi, as a result of interfering in systemic $\mathrm{T} / \mathrm{B}$ cell functions and in local destructive events, primarily osteoclast and FLS activity. Thus, efficacy resulted from interfering with the activity of multiple cells, and perhaps reducing compensatory disease mechanisms. Importantly, intermittent suppression of individual targets was sufficient to modulate disease activity and reduce adverse events. Overall, the greater and broader anti-rheumatic action of adding SYK inhibition to a JAK inhibition therapy hold experimental promise but will need confirmation from clinical studies.

\section{Conclusions}

The present study collectively suggests that dual JAK + SYK inhibition with selective, potent and orally bioavailable small molecules could complement the current arsenal of tools in development for the treatment of rheumatoid arthritis and likely other inflammatory and autoimmune disorders.

\section{Additional files}

\begin{abstract}
Additional file 1: Potency, selectivity and pharmacokinetics of tofacitinib/CP-690,550 (Janus kinase inhibitor (JAKi)) and PRT-062607 (spleen tyrosine kinase inhibitor (SYKi)). a, b Human cell lines were pre-incubated with increasing concentrations of JAKi or SYKi $(0.005$ to $5 \mu \mathrm{M})$ for $1 \mathrm{~h}$ and then stimulated with either $100 \mathrm{ng} / \mathrm{ml} \mathrm{rmlL}-6$ for 15 minutes or $10 \mathrm{\mu g} / \mathrm{ml}$ anti-lgM for 5 minutes. Cells were fixed, permeabilized, stained with anti-STAT3(pY705)-Alexa Fluor 647 or anti-BLNK(pY84)-Alexa Fluor 488 and quantified by flow cytometry. Half maximal inhibitory concentration $\left(\mathcal{C}_{50}\right)$ was extrapolated from an inhibition vs log (concentration) curve. c Collagen-induced arthritis (CIA) model. DBA/1 mice were immunized on day 0 with type II collagen $(100 \mu \mathrm{g} / \mathrm{mouse}$, subcutaneous administration (s.c.)) emulsified in complete Freund's adjuvant (CFA) and boosted on day 21. Starting on day 30 , when disease was mild, mice were orally treated once a day with increasing doses of JAKi (3.75 to $30 \mathrm{mg} / \mathrm{kg}$ ). Graph shows mean for 6-8 mice/group. d Collagen antibody-induced arthritis (CAIA) model. BALB/c mice received a cocktail of monoclonal antibodies (2 mg, intravenous administration (i.v.)) directed against type $\|$ collagen on day 0 and a lipolysaccharide challenge (70 $\mu$ g, intraperitoneal administration (i.p.)) on day 3. Twice daily treatment with $30 \mathrm{mg} / \mathrm{kg}$ SYKi started on day 4. Graph shows mean for 6-8 mice/group. For monitoring both CIA and CAIA models, each paw was scored individually on a scale of $0-4$, with 4 indicating the most severe swelling and erythema. e DBA 1 mice received a single oral dose of JAKi (20 mg/kg) or SYKi (30 mg/kg) and plasmatic drug concentration was determined by liquid chromatography-tandem mass spectrometry. Graph shows mean for 2-7 mice/group and a line representing $I C_{50}$ values obtained in $\mathbf{a}$ and $\mathbf{b}$. (PDF $755 \mathrm{~kb}$ )
\end{abstract}

Additional file 2: Clinical and immunological comparison of acute versus chronic glucose-6-phosphate isomerase (G6Pl)-induced arthritis model in mice. a Diagram summarizing the experimental protocol followed in Figs. 1, 2, 3, 4 and 5 (see "Methods" for more details). b Time course for arthritis scores clearly showing moderate and acute arthritis in G6PI-immunized mice, and severe and chronic arthritis in T regulatory cell (Treg)-depleted and G6PI-immunized mice. c Proportion of CD25 $5^{\text {hi Foxp3 }}{ }^{+}$ Treg cells in $\mathrm{CD}^{+} \mathrm{CD}^{+}$cells at the time of immunization (day 0). $\mathbf{d}$ Numbers of total cells from inguinal lymph nodes and e leucocyte counts in peripheral blood at day 6 post-immunization. $\mathbf{f}$ Cytokine secretion by splenocytes isolated on day 31 and stimulated in vitro with $20 \mu \mathrm{g} / \mathrm{ml} \mathrm{G6PI}$ for $72 \mathrm{~h}$. Graphs show mean ( \pm standard error of the mean) for 3-6 mice/group, ${ }^{*} p<0.05$ versus naive control, ${ }^{*} p<0.05$ versus G6Pl-immunized mice. s.c. subcutaneous administration, i.v. intravenous administration, i.p. intraperitoneal administration, p.o. oral administration, QD one dose a day. (PDF 521 kb)

Additional file 3: Effect of Janus kinase inhibitor (JAKi)/spleen tyrosine kinase inhibitor (SYKi) treatment on body weight and cell viability. a DBA 1 mice were immunized with glucose-6-phosphate isomerase (G6P) + complete Freund's adjuvant (CFA) on day 0. b CD-1 mice were immunized with keyhole limpet hemocyanin (KLH) on day 14 ( $T$ cell-dependent antibody response (TDAR) assay). $\mathbf{a}, \mathbf{b}$ Relative body weight to day 0 (before treatment started) was recorded regularly. As expected, naive animals progressively gained weight over time and treatment with the glucocorticoid prednisone induced the most significant decrease in body weight. G6PI immunization triggered the development of arthritis and, therefore, vehicle-treated animals initially lost weight and then slowly recovered. Modest changes were observed in vehicle-exposed mice upon KLH immunization. Body weight in mice daily treated with single or dual JAK/SYK inhibition was comparable to, or even better than, vehicle-treated animals, clearly showing that treatment with JAKi + SYKi did not negatively impact the general wellbeing of mice. c HepG2 cells were exposed for $72 \mathrm{~h}$ to increasing doses of JAKi/SYKi $(0.5,5$ 
or $50 \mu \mathrm{M}$ ) or diclofenac (positive control of hepatotoxicity) and mitochondria activity was evaluated by Alamar Blue fluorescence. JAKi did not show any cytotoxic effect at the assayed concentrations. SYKi significantly decreased cell viability only at the highest dose $(50 \mu \mathrm{M})$. Importantly, plasma levels of SYKi peaked at 3-4 $\mu \mathrm{M}$ and for a very short time (see Additional file 1e); therefore, higher and sustained concentrations are never reached in vivo. These data show that combined inhibition of JAK + SYK does not result in higher general toxicity. Graphs show mean ( \pm standard error of the mean) for 3-6 mice/ group or 2-10 replicates/condition, ${ }^{*} p<0.05$ versus media (untreated cells). Med media, Diclo diclofenac, Predni prednisolone. (PDF $432 \mathrm{~kb}$ )

\section{Abbreviations}

ACR20: American College of Rheumatology $20 \%$ improvement; AUC: area under the curve; BrdU: 5-bromo-2-deoxyuridine; BSA: bovine serum albumin; CAIA: collagen antibody-induced arthritis; CDC: cell-mediated cytotoxicity; CFA: complete Freund's adjuvant; CIA: collagen-induced arthritis; DC: dendritic cell; DMARD: disease modifying anti-rheumatic drug; DMEM: Dulbecco's modified Eagle's medium; DMSO: dimethyl sulfoxide; EC: effector cells; ELISA: enzyme-linked immunosorbent assay; FBS: fetal bovine serum; FLS: fibroblast-like synoviocyte; G6PI: glucose-6-phosphate isomerase; GM-CSF: granulocyte macrophage colonystimulating factor; $H \& E$ : hematoxylin and eosin; $I_{50}$ : half maximal inhibitory concentration; IL: interleukin; IFN: interferon; i.p.: intraperitoneal administration; i.v: intravenous administration; JAK: Janus kinase; JAKi: Janus kinase inhibitor; kDa: kiloDalton; KLH: keyhole limpet hemocyanin; MAPK: mitogen-activated protein kinase; MMP: matrix metalloproteinase; MTX: methotrexate; NK: natural killer cell; NSAID: non-steroidal anti-inflammatory drug; PBS: phosphate-buffered saline; p.o.: oral administration (per os); PBMC: peripheral blood mononuclear cell; OVA: ovalbumin; QD: one dose a day (quaque die); RA: rheumatoid arthritis; RANKL: receptor activator of nuclear factor kappa-B ligand; rhu: recombinant human; s.c.: subcutaneous administration; SYK: spleen tyrosine kinase; SYKi: spleen tyrosine kinase inhibitor; TC: target cells; TDAR: T cell-dependent antibody response; Th: T helper; TNF: tumor necrosis factor; TRAP: tartrate-resistant acid phosphatase; Treg: regulatory $T$ cells.

\section{Competing interests}

The authors declare that they have no competing interests. MP, LG and JR are current employees of Draconis Pharma S.L., a biotechnology company focused on providing scientific and technological services.

\section{Authors' contributions}

ALG conceived, designed and performed the experiments, acquired, analyzed and interpreted the data, and wrote the paper. MP and CC helped to perform the experiments and to acquire the data, and revised the manuscript. IDC, VR, PLVL and ED carried out the experiments with osteoclasts and revised the manuscript. FM carried out the experiments with synoviocytes and revised the manuscript. FS and HDC carried out the experiments with memory cells and revised the manuscript. LG, TK and JR provided insightful guidance and critical appraisal of the manuscript. JR also contributed to the conception and design of the experiments and helped to draft the paper. All authors read and approved the manuscript.

\section{Acknowledgements}

We gratefully acknowledge the technical help of Jordi Vilar, Noelia Ardanaz, Ma Teresa Gamero, Eva Medina, Jordi Romaguera, Lara de Llobet, Juana Peña and Cristina Gerbolés. We also thank Dr. Azucena Salas for easing the purchase of etanercept. We are indebted to Iren Schulz for administrative assistance in the ITN "Osteoimmune". This research was supported by the Seventh Framework Programme and Marie Curie Actions (European Commission, FP7-PEOPLE-2011-ITN-289150 "Osteoimmune"). ALG holds an ITN postdoctoral fellowship and IDC, FS and FM are supported by ITN doctoral fellowships. Some of this work was also funded by Innovative Medicines Initiative (project BTCure 115241) and the Leibniz Graduate School for Rheumatology.

\section{Author details}

${ }^{1}$ Draconis Pharma S.L., Calle Pallars 179, Barcelona, Spain. ${ }^{2}$ Deutsches Rheuma-Forschungszentrum, Berlin, Germany. ${ }^{3}$ Radboud University Medical Center, Nijmegen, Netherlands. ${ }^{4}$ Universitätsklinikum, Jena, Germany. ${ }^{5}$ Laboratory of Genetics, Department of Biotechnology, Agricultural University of Athens, Athens, Greece. 'Biomedical Sciences Research Center "Alexander Fleming", Vari, Greece.
Received: 4 September 2015 Accepted: 19 November 2015

Published online: 10 December 2015

\section{References}

1. Paula FS, Alves JD. Non-tumor necrosis factor-based biologic therapies for rheumatoid arthritis: present, future, and insights into pathogenesis. Biol Targets Therapy. 2014;8:1-12.

2. Hammaker D, Firestein GS. "Go upstream, young man": lessons learned from the p38 saga. Ann Rheum Dis. 2010;69:77-82.

3. Foster JG, Blunt MD, Carter E, Ward SG. Inhibition of PI3K signaling spurs New therapeutic opportunities in inflammatory/autoimmune diseases and hematological malignancies. Pharmacol Rev. 2012;64(4):1027-54.

4. Smolen JS, Beaulieu A, Rubbert-Roth A, Ramos-Remus C, Rovensky J, Alecock $E$, et al. Effect of interleukin-6 receptor inhibition with tocilizumab in patients with rheumatoid arthritis (OPTION study): a double-blind, placebo-controlled, randomised trial. Lancet. 2008;371(9617):987-97.

5. Baslund B, Tvede N, Danneskiold-Samsoe B, Larsson P, Panayi G, Petersen J, et al. Targeting interleukin-15 in patients with rheumatoid arthritis - a proof-of-concept study. Arthritis Rheum. 2005;52(9):2686-92.

6. Milici AJ, Kudlacz EM, Audoly L, Zwillich S, Changelian P. Cartilage preservation by inhibition of Janus kinase 3 in two rodent models of rheumatoid arthritis. Arthritis Res Ther. 2008;10(1):R14. doi: 10.1186/ar2365. Epub 2008 Jan 30.

7. Fridman JS, Scherle PA, Collins R, Burn TC, Li YL, Li J, et al. Selective inhibition of JAK1 and JAK2 is efficacious in rodent models of arthritis: preclinical characterization of INCB028050. J Immunol. 2010;184(9):5298-307.

8. van Vollenhoven RF, Fleischmann R, Cohen S, Lee EB, Garcia Meijide JA, Wagner $\mathrm{S}$, et al. Tofacitinib or adalimumab versus placebo in rheumatoid arthritis. N Engl J Med. 2012;367(6):508-19.

9. Fleischmann R, Kremer J, Cush J, Schulze-Koops H, Connell CA, Bradley JD, et al. Placebo-controlled trial of tofacitinib monotherapy in rheumatoid arthritis. N Engl J Med. 2012;367(6):495-507.

10. van der Heijde D, Tanaka Y, Fleischmann R, Keystone E, Kremer J, Zerbini C, et al. Tofacitinib (CP-690,550) in patients with rheumatoid arthritis receiving methotrexate: twelve-month data from a twenty-fourmonth phase III randomized radiographic study. Arthritis Rheum. 2013; 65(3):559-70.

11. Charles-Schoeman C, Burmester G, Nash P, Zerbini CA, Soma K, Kwok K, et al. Efficacy and safety of tofacitinib following inadequate response to conventional synthetic or biological disease-modifying antirheumatic drugs. Ann Rheum Dis. 2015; doi: 10.1136/annrheumdis-2014-207178. [Epub ahead of print].

12. Kremer JM, Bloom BJ, Breedveld FC, Coombs JH, Fletcher MP, Gruben D, et al. The safety and efficacy of a JAK inhibitor in patients with active rheumatoid arthritis results of a double-blind, placebo-controlled phase lla trial of three dosage levels of CP-690,550 versus placebo. Arthritis Rheum. 2009;60(7):1895-905.

13. Burmester GR, Blanco R, Charles-Schoeman C, Wollenhaupt J, Zerbini C, Benda B, et al. Tofacitinib (CP-690,550) in combination with methotrexate in patients with active rheumatoid arthritis with an inadequate response to tumour necrosis factor inhibitors: a randomised phase 3 trial. Lancet. 2013;381(9865):451-60.

14. Lee EB, Fleischmann R, Hall S, Wilkinson B, Bradley JD, Gruben D, et al. Tofacitinib versus Methotrexate in rheumatoid arthritis. New Engl J Med. 2014;370(25):2377-86.

15. Bajpai M, Chopra P, Dastidar SG, Ray A. Spleen tyrosine kinase: a novel target for therapeutic intervention of rheumatoid arthritis. Expert Opin Inv Drug. 2008;17(5):641-59.

16. Sada K, Takano T, Yanagi S, Yamamura H. Structure and function of Syk protein-tyrosine kinase. J Biochem-Tokyo. 2001;130(2):177-86.

17. Yanagi S, Inatome R, Ding JY, Kitaguchi H, Tybulewicz VLJ, Yamamura H. Syk expression in endothelial cells and their morphologic defects in embryonic Syk-deficient mice. Blood. 2001;98(9):2869-71.

18. Mocsai A, Humphrey MB, Van Ziffle JAG, Hu YM, Burghardt A, Spusta SC, et al. The immunomodulatory adapter proteins DAP12 and Fc receptor gamma-chain (FcR gamma) regulate development of functional osteoclasts through the Syk tyrosine kinase. Proc Natl Acad Sci U S A. 2004;101(16): 6158-63.

19. Coffey G, DeGuzman F, Inagaki M, Pak Y, Delaney SM, Ives D, et al. Specific inhibition of spleen tyrosine kinase suppresses leukocyte immune function and inflammation in animal models of rheumatoid arthritis. J Pharmacol Exp Ther. 2012;340(2):350-9. 
20. Schubert D, Maier B, Morawietz L, Krenn V, Kamradt T. Immunization with glucose-6-phosphate isomerase induces $T$ cell-dependent peripheral polyarthritis in genetically unaltered mice. J Immunol. 2004;172(7):4503-9.

21. Frey $\mathrm{O}$, Reichel $\mathrm{A}$, Bonhagen $\mathrm{K}$, Morawietz $\mathrm{L}$, Rauchhaus $U$, Kamradt $\mathrm{T}$. Regulatory $T$ cells control the transition from acute into chronic inflammation in glucose-6-phosphate isomerase-induced arthritis. Ann Rheum Dis. 2010;69(8):1511-8.

22. Pettit AR, Ji H, von Stechow D, Muller R, Goldring SR, Choi YW, et al. TRANCE/RANKL knockout mice are protected from bone erosion in a serum transfer model of arthritis. Am J Pathol. 2001;159(5):1689-99.

23. Yang S, Hollister AM, Orchard EA, Chaudhery SI, Ostanin DV, Lokitz SJ, et al. Quantification of bone changes in a collagen-induced arthritis mouse model by reconstructed three dimensional micro-CT. Biol Proced Online. 2013;15:8. doi: 10.1186/1480-9222-15-8. eCollection 2013.

24. Schindelin J, Arganda-Carreras I, Frise E, Kaynig V, Longair M, Pietzsch T, et al. Fiji: an open-source platform for biological-image analysis. Nat Methods. 2012; 9(7):676-82.

25. Douni E, Rinotas V, Makrinou E, Zwerina J, Penninger JM, Eliopoulos E, et al. A RANKL G278R mutation causing osteopetrosis identifies a functional amino acid essential for trimer assembly in RANKL and TNF. Hum Mol Genet. 2012;21(4):784-98

26. Matsumoto I, Zhang H, Yasukochi T, Iwanami K, Tanaka Y, Inoue A, et al. Therapeutic effects of antibodies to tumor necrosis factor-alpha, interleukin6 and cytotoxic T-lymphocyte antigen 4 immunoglobulin in mice with glucose-6-phosphate isomerase induced arthritis. Arthritis Res Ther. 2008; 10(3):R66. doi: 10.1186/ar2437. Epub 2008 Jun 5.

27. Saxne T, Palladino MA, Heinegard D, Talal N, Wollheim FA. Detection of tumor necrosis factor-alpha but not tumor necrosis factor-beta in rheumatoid-arthritis synovial-fluid and serum. Arthritis Rheum. 1988;31(8): $1041-5$

28. Ziolkowska N, Koc A, Luszczykiewicz G, Ksiezopolska-Pietrzak K, Klimczak E, Chwalinska-Sadovska $\mathrm{H}$, et al. High levels of IL-17 in rheumatoid arthritis patients: IL-15 triggers in vitro IL-17 production via cyclosporin A-sensitive mechanism. J Immunol. 2000;164(5):2832-8.

29. Hoyer BF, Mumtaz IM, Yoshida T, Hiepe F, Radbruch A. How to cope with pathogenic long-lived plasma cells in autoimmune diseases. Ann Rheum Dis. 2008;67 Suppl 3:iii87-89.

30. Ghoreschi K, Jesson MI, Li XO, Lee JL, Ghosh S, Alsup JW, et al. Modulation of innate and adaptive immune responses by tofacitinib (CP-690,550). J Immunol. 2011;186(7):4234-43.

31. Townsend RM, Kliwinski C, Kukral D, Postelnek J, Krishnan B, Killar L, et al. Prophylactic administration of abatacept prevents disease induction and bone destruction in a rat model of collagen-induced arthritis. Ann Rheum Dis. 2005; 64:439-9.

32. Zhong JX, Yang P, Muta K, Dong R, Marrero M, Gong FL, et al. Loss of Jak2 selectively suppresses DC-mediated innate immune response and protects mice from lethal dose of LPS-induced septic shock. PLoS One. 2010;5(3):e9593. doi: 10.1371/journal.pone.0009593.

33. Heine A, Held SAE, Daecke SN, Wallner S, Yajnanarayana SP, Kurts C, et al. The JAK-inhibitor ruxolitinib impairs dendritic cell function in vitro and in vivo. Blood. 2013;122(7):1192-202

34. Sallusto F, Lanzavecchia A. Efficient presentation of soluble-antigen by cultured human dendritic cells is maintained by granulocyte-macrophage colony-stimulating factor plus interleukin-4 and down-regulated by tumor-necrosis-factor-alpha. J Exp Med. 1994;179(4):1109-18.

35. Jakus Z, Simon E, Balazs B, Mocsai A. Genetic Deficiency of Syk Protects Mice From Autoantibody-Induced Arthritis. Arthritis Rheum. 2010;62(7):1899-910.

36. LeibundGut-Landmann S, Osorio F, Brown GD, Sousa CRE. Stimulation of dendritic cells via the dectin-1/Syk pathway allows priming of cytotoxic T-cell responses. Blood. 2008;112(13):4971-80.

37. Weinblatt ME, Kremer JM, Bankhurst AD, Bulpitt KJ, Fleischmann RM, Fox RI, et al. A trial of etanercept, a recombinant tumor necrosis factor receptor: FC fusion protein, in patients with rheumatoid arthritis receiving methotrexate. New Engl J Med. 1999;340(4):253-9.

38. Lipsky PE, van der Heijde DMFM, St Clair EW, Furst DE, Breedveld FC, Kalden $J R$, et al. Infliximab and methotrexate in the treatment of rheumatoid arthritis. New Engl J Med. 2000;343(22):1594-602.

39. Clair EWS, van der Heijde DMFM, Smolen JS, Maini RN, Bathon JM, Emery $P$, et al. Combination of infliximab and methotrexate therapy for early rheumatoid arthritis - A randomized, controlled trial. Arthritis Rheum. 2004:50(11):3432-43.
40. Conklyn M, Andresen C, Changelian P, Kudlacz E. The JAK3 inhibitor CP-690550 selectively reduces NK and CD8 + cell numbers in cynomolgus monkey blood following chronic oral dosing. J Leukocyte Biol. 2004;76(6): 1248-55.

41. Kudlacz E, Perry B, Sawyer P, Conklyn M, McCurdy S, Brissette W, et al. The novel JAK-3 inhibitor CP-690550 is a potent immunosuppressive agent in various murine models. Am J Transplant. 2004;4(1):51-7.

42. Nosaka T, vanDeursen J, Tripp RA, Thierfelder WE, Witthuhn BA, McMickle AP, et al. Defective lymphoid development in mice lacking Jak3. Blood. 1995;86(10):486-6.

43. Thomis DC, Gurniak CB, Tivol E, Sharpe AH, Berg L. Defects in B-lymphocyte maturation and T-lymphocyte activation in mice lacking Jak3. Science. 1995; 270(5237):794-7.

44. Cao XQ, Shores EW, Huli J, Anver MR, Kelsall BL, Russell SM, et al. Defective lymphoid development in mice lacking expression of the common cytokine receptor-gamma chain. Immunity. 1995;2(3):223-38.

45. Ranson T, Vosshenrich CAJ, Corcuff E, Richard O, Muller W, Di Santo JP. IL-15 is an essential mediator of peripheral NK-cell homeostasis. Blood. 2003; 101(12):4887-93.

46. Lio CWJQ, Hsieh CS. A two-step process for thymic regulatory $T$ cell development. Immunity. 2008;28(1):100-11.

47. Burchill MA, Yang JY, Vang KB, Moon JJ, Chu HH, Lio CWJ, et al. Linked $T$ cell receptor and cytokine signaling govern the development of the regulatory T cell repertoire. Immunity. 2008;28(1):112-21.

48. Sewgobind VDKD, Quaedackers ME, van der Laan LJW, Kraaijeveld R, Korevaar SS, Chan G, et al. The Jak inhibitor CP-690,550 preserves the function of CD4 + CD25brightFoxP3 + regulatory $T$ cells and inhibits effector T cells. Am J Transplant. 2010;10(8):1785-95.

49. Rosengren S, Corr M, Firestein GS, Boyle DL. The JAK inhibitor CP-690,550 (tofacitinib) inhibits TNF-induced chemokine expression in fibroblast-like synoviocytes: autocrine role of type I interferon. Ann Rheum Dis. 2012;71(3): 440-7.

50. Kao CY, Chen Y, Thai P, Wachi S, Huang F, Kim C, et al. IL-17 markedly up-regulates beta-defensin-2 expression in human airway epithelium via JAK and NF-kappa B signaling pathways. J Immunol. 2004;173(5):3482-91.

51. Huang F, Kao CY, Wachi S, Thai $P$, Ryu J, Wu R. Requirement for both JAK-Mediated PI3K signaling and ACT1/TRAF6/TAK1-dependent NF-kappa B activation by IL-17A in enhancing cytokine expression in human airway epithelial cells'. J Immunol. 2007;179(10):6504-13.

52. Lowin T, Straub RH. Integrins and their ligands in rheumatoid arthritis. Arthritis Res Ther. 2011;13(5):244. doi: 10.1186/ar3464. Epub 2011 Oct 28.

53. Pap T, van der Laan WH, Aupperle KR, Gay RE, Verheijen JH, Firestein GS, et al. Modulation of fibroblast-mediated cartilage degradation by articular chondrocytes in rheumatoid arthritis. Arthritis Rheum. 2000;43(11):2531-6.

54. Li P, Schwarz EM, O'Keefe RJ, Ma L, Looney RJ, Ritchlin CT, et al. Systemic tumor necrosis factor alpha mediates an increase in peripheral CD11b(high) osteoclast precursors in tumor necrosis factor alphatransgenic mice. Arthritis Rheum. 2004;50(1):265-76.

55. Yao ZQ, Li P, Zhang Q, Schwarz EM, Keng P, Arbini A, et al. Tumor necrosis factor-alpha increases circulating osteoclast precursor numbers by promoting their proliferation and differentiation in the bone marrow through up-regulation of c-Fms expression. J Biol Chem. 2006;281(17): 11846-55.

56. Boyle WJ, Simonet WS, Lacey DL. Osteoclast differentiation and activation. Nature. 2003:423(6937):337-42.

57. Teitelbaum SL. The alpha(v)beta(3) integrin mediates osteoclastic bone resorption. J Bone Miner Res. 2000;15(4):819-9.

58. Takayanagi H, lizuka H, Juji T, Nakagawa T, Yamamoto A, Miyazaki T, et al. Involvement of receptor activator of nuclear factor kappa B ligand/ osteoclast differentiation factor in osteoclastogenesis from synoviocytes in rheumatoid arthritis. Arthritis Rheum. 2000;43(2):259-69.

59. Yeo L, Toellner KM, Salmon M, Filer A, Buckley CD, Raza K, et al. Cytokine mRNA profiling identifies $B$ cells as a major source of RANKL in rheumatoid arthritis. Ann Rheum Dis. 2011;70(11):2022-8.

60. Hauser AE, Debes GF, Arce S, Cassese G, Hamann A, Radbruch A, et al. Chemotactic responsiveness toward ligands for CXCR3 and CXCR4 is regulated on plasma blasts during the time course of a memory immune response. J Immunol. 2002;169(3):1277-82.

61. Tokoyoda K, Zehentmeier S, Chang HD, Radbruch A. Organization and maintenance of immunological memory by stroma niches. Eur J Immunol. 2009;39(8):2095-9. 
62. Kondrack RM, Harbertson J, Tan JT, McBreen ME, Surh CD, Bradley LM. Interleukin 7 regulates the survival and generation of memory CD4 cells. J Exp Med. 2003;198(12):1797-806.

63. Benson MJ, Dillon SR, Castigli E, Geha RS, Xu SL, Lam KP, et al. Cutting edge: The dependence of plasma cells and independence of memory $B$ cells on BAFF and APRIL. J Immunol. 2008;180(6):3655-9.

64. Schweighoffer E, Vanes L, Nys J, Cantrell D, McCleary S, Smithers N, et al. The BAFF receptor transduces survival signals by Co-opting the B cell receptor signaling pathway. Immunity. 2013;38(3):475-88.

Submit your next manuscript to BioMed Central and we will help you at every step:

- We accept pre-submission inquiries

- Our selector tool helps you to find the most relevant journal

- We provide round the clock customer support

- Convenient online submission

- Thorough peer review

- Inclusion in PubMed and all major indexing services

- Maximum visibility for your research 